Supporting information for the article

\title{
Dual Electrospray Ionization Enhancement of Proteins Enabled by DMSO Supercharging Reagent
}

\author{
Dmitry B. Eremin ${ }^{\dagger, \dagger}$ and Valery V. Fokin ${ }^{\dagger,+} *$ \\ ${ }^{\dagger}$ Bridge Institute, University of Southern California, 1002 Childs Way, Los Angeles, California 90089-3502, United States \\ ¥ Loker Hydrocarbon Research Institute and Department of Chemistry, University of Southern California, Los Angeles, \\ California 90089-1661, United States \\ *E-mail: fokin@usc.edu
}

\section{CONTENTS}

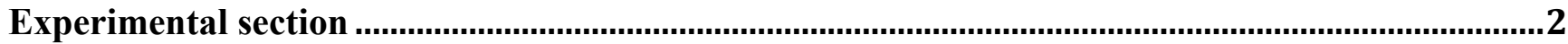

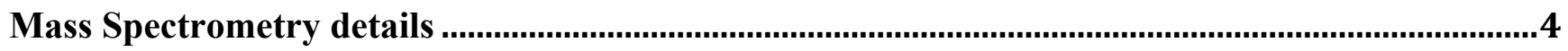

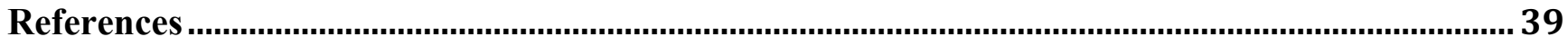




\section{Experimental section}

General considerations. MeCN (LC/MS grade), DMSO (HPLC grade), $m$-nitrobenzylic alcohol (ACS grade), water (LC/MS grade), and formic acid (LC/MS grade) were obtained from Fisher Scientific and Millipore-Sigma and used as received. Tunemix solution for calibration was ordered from Agilent Technologies. DMSO solution $10 \mathrm{v} / \mathrm{v} \%$ was prepared by mixing $2 \mathrm{~mL}$ of DMSO with $18 \mathrm{~mL}$ of water and stored at r.t. Aliquot sampling was conducted by using Hamilton syringes or RAININ pipets. $10 \mathrm{~mL}$ Hamilton syringe (1010RN) was used for injection of DMSO solution via syringe pump (KD Scientific Inc).

Protein sample preparation. BSA and Lysozyme were obtained from Millipore-Sigma. For each protein $0.2 \mathrm{mg} \mathrm{mL}^{-1}$ solution $(1 \mathrm{~mL})$ was prepared in LC/MS water in $1.8 \mathrm{~mL}$ screw top glass vials (Agilent). A mixture sample was prepared by mixing two solutions in $1: 1$ ratio.

Thioredoxin reductase - rTrxRh2 (gene TVAG_123560) was kindly provided by Prof. Lars Eckmann and Dr. Yukiko Miyamoto (UCSD) and used as received. The $50 \mu \mathrm{L}$ of a solution of $0.0625 \mu \mathrm{g} \mathrm{mL}^{-1}$ concentration of protein were transferred into a $300 \mu \mathrm{L}$ fixed insert screw top glass vial (Agilent). $2 \mu \mathrm{L}$ were injected for analysis.

Amelogenin - rM155 isomorph 3 was kindly provided by Prof. Janet Moradian-Oldak and Dr. Rucha Arun Bapat (USC) and used as received. The $50 \mu \mathrm{L}$ of a solution of $\sim 0.5 \mu \mathrm{g} \mathrm{mL}^{-1}$ concentration of protein were transferred into a $300 \mu \mathrm{L}$ fixed insert screw top glass vial (Agilent). $1 \mu \mathrm{L}$ was injected for analysis.

Kappa-Opioid Receptor (KOR) and adenosine receptor $\left(\mathrm{A}_{2 \mathrm{~A}}\right)$ were kindly provided by Prof. Vadim Cherezov and Dr. Hamidreza Shaye (USC) and used as received. The $10 \mu \mathrm{L}$ of a solution of $\sim 0.2 \mu \mathrm{g} \mathrm{mL}{ }^{-1}$ concentration of protein were transferred into a $300 \mu \mathrm{L}$ fixed insert screw top glass vial (Agilent). $1 \mu \mathrm{L}$ was injected for analysis.

LC-ESI-(+)MS experiments. Mass spectra were measured using an Agilent 6545XT qToF instrument coupled with 1290 LC system. QToF mass spectrometer is equipped with a dual AJS electrospray ionization source. In positive ion mode ionization parameters are the following: Capillary Voltage $-4.5 \mathrm{kV}$, Nozzle Voltage $-2.0 \mathrm{kV}$, nitrogen was applied as a nebulizer gas $45 \mathrm{psi}$, sheath gas $12 \mathrm{~L} \mathrm{~min}^{-1}$, $275^{\circ} \mathrm{C}$, dry gas $8 \mathrm{~L} \mathrm{~min}^{-1}, 300{ }^{\circ} \mathrm{C}$, and collision gas. Spectra were recorded in $\mathrm{m} / z 100-3000$ range. For external calibration and tuning a low-concentration tuning mix solution by Agilent Technologies was utilized diluted further 10:1. Samples were injected using LC system. Flow injection was used for BSA and lysozyme ( $1 \mu \mathrm{L}$ injections) $0.5 \mathrm{~mL} \mathrm{~min}^{-1}$ flow with 50:50 water:MeCN, 
and HPLC separation was used for all other samples using PLRP-S $1000 \AA$ (5 $\mu \mathrm{m}, 50 \times 2.1 \mathrm{~mm})$. All the MS spectra were recorded at $1 \mathrm{~Hz}$.

For all injections of protein samples reference nebulizer in the dual source was either disables, or a DMSO solution was sprayed through it. A syringe pump was used to introduce $0-15 \%$ DMSO solution in water at $0.3 \mathrm{~mL} \mathrm{~min}^{-1}$ flow rate. DMSO was applied within a window of protein elution.

HPLC parameters for BSA, lysozyme, and thioredoxin reductase:

Column was thermostated at $60{ }^{\circ} \mathrm{C}$. Gradient elution with a flow rate of $0.5 \mathrm{~mL} \mathrm{~min}{ }^{-1}$ was applied with mobile phase $\mathrm{A}-$ water, $0.1 \%$ formic acid; phase $\mathrm{B}-\mathrm{MeCN}, 0.1 \%$ formic acid. The gradient conditions were as follows: start with $20 \% \mathrm{~B}$, hold for $4 \mathrm{~min}$, ramp $20 \%$ to $40 \%$ in $1 \mathrm{~min}$, followed by $5 \mathrm{~min}$ ramp $40 \%$ to $70 \%$, and ramp $70 \%$ to $90 \%$ in $1 \mathrm{~min}$. Post-run time for system equilibration $-4 \mathrm{~min}$.

HPLC parameters for amelogenin:

Column was thermostated at $70{ }^{\circ} \mathrm{C}$. Gradient elution with a flow rate of $0.5 \mathrm{~mL} \mathrm{~min}{ }^{-1}$ was applied with mobile phase $\mathrm{A}-$ water, $0.1 \%$ formic acid; phase $\mathrm{B}-\mathrm{MeCN}, 0.1 \%$ formic acid. The gradient conditions were as follows: start with $20 \% \mathrm{~B}$, hold for $4 \mathrm{~min}$, ramp $20 \%$ to $40 \%$ in $2 \mathrm{~min}$, followed by $5 \mathrm{~min}$ ramp $40 \%$ to $70 \%$, and ramp $70 \%$ to $90 \%$ in $1 \mathrm{~min}$. B was returned to $20 \%$ in $0.1 \mathrm{~min}$ and post-run time for system equilibration was $4 \mathrm{~min}$.

HPLC parameters for KOR and $\mathrm{A}_{2 \mathrm{~A}}:^{1}$

Column was thermostated at $70{ }^{\circ} \mathrm{C}$. Gradient elution with a flow rate of $0.2 \mathrm{~mL} \mathrm{~min}{ }^{-1}$ was applied with mobile phase $\mathrm{A}$ - water, $0.1 \%$ formic acid; phase B - 85\% n-propanol in water, $0.1 \%$ formic acid. The gradient conditions were as follows: start with $20 \% \mathrm{~B}$, ramp $20 \%$ to $30 \%$ in $2 \mathrm{~min}$, followed by 4 min ramp $30 \%$ to $65 \%$, and ramp $65 \%$ to $95 \%$ in $14 \mathrm{~min}$. B was returned to $20 \%$ in 2 min and post-run time for system equilibration was $5 \mathrm{~min}$.

The spectra were processed using the Agilent MassHunter 10.0 and the Agilent BioConfirm 10.0 software packages, then the spectra were converted to txt format and post-processed using the software ${ }^{2}$ written in Python using the NumPy ${ }^{3-4}$ and Pandas ${ }^{5}$ packages. Spectra were processed by pyOpenMS package. ${ }^{6-7}$ Mass spectra and deconvoluted spectra were plotted using the Matplotlib package. ${ }^{8-9}$ 


\section{Mass Spectrometry details}

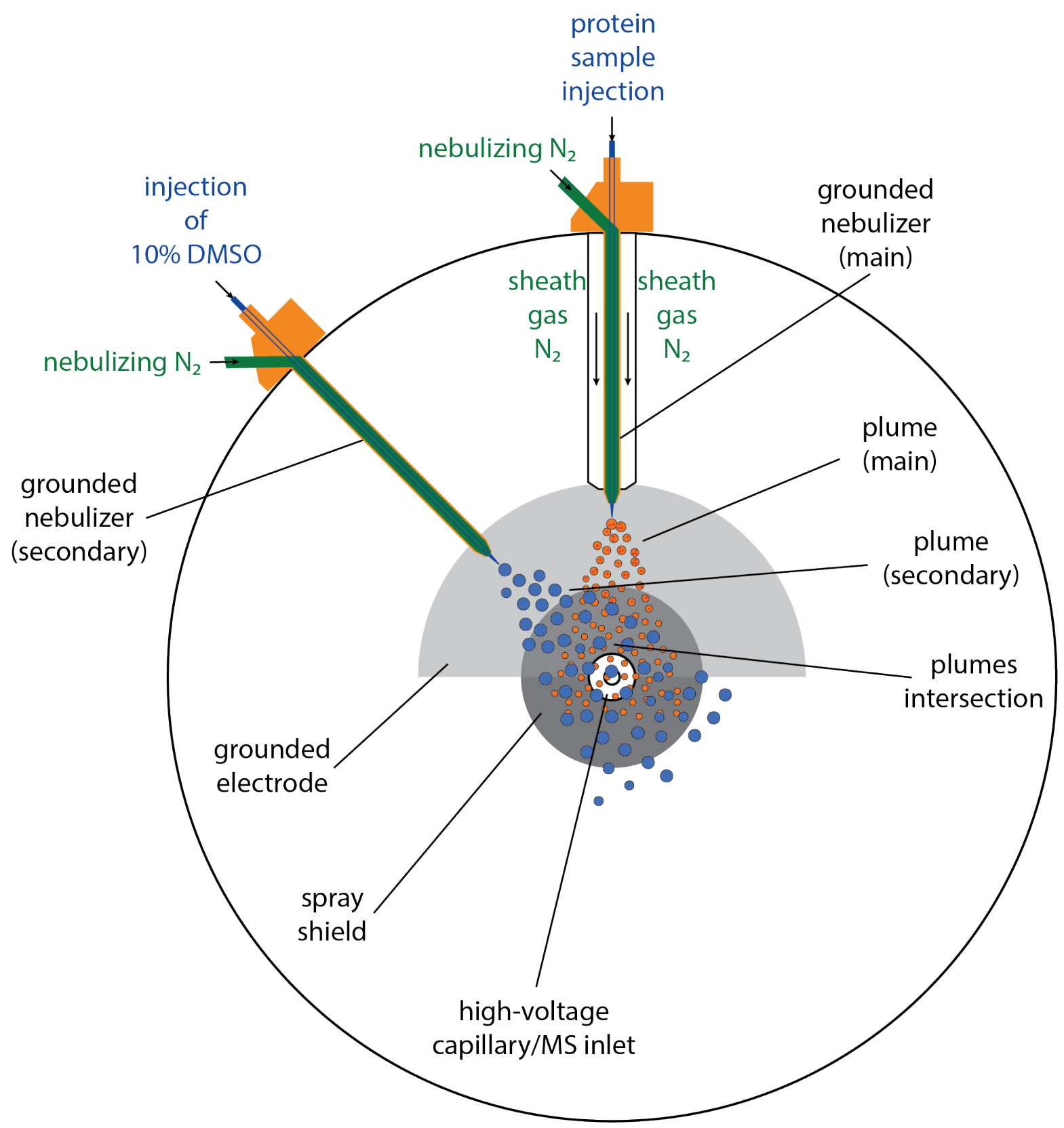

Figure S1. Scheme of a dual AJS ionization source used for ionization enhancement.

First, source parameters were optimized, followed by optimization of dual spray system and DMSO content. Optimization of each set of parameters was performed within one day with a freshly prepared protein sample. 


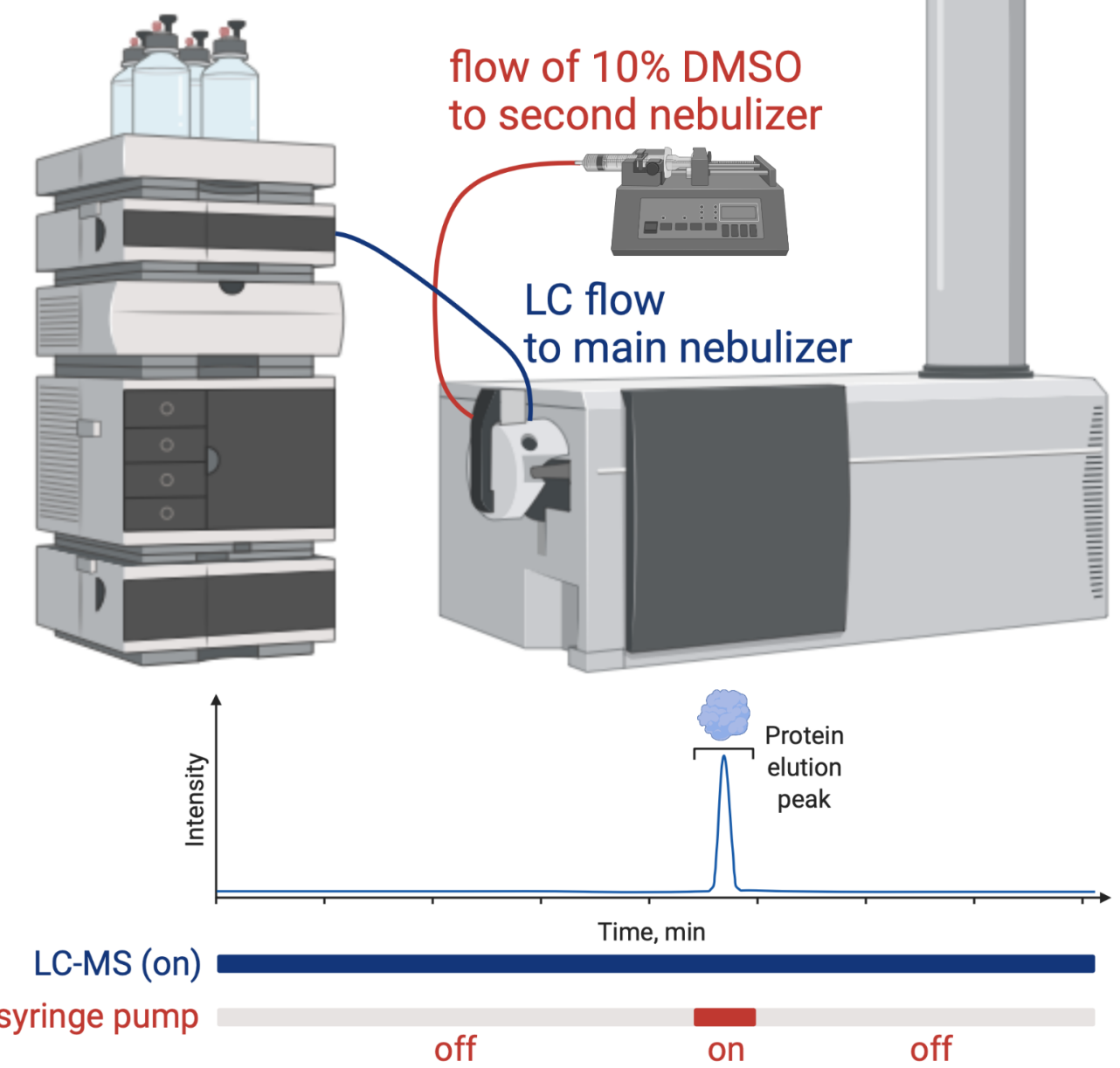

Figure S2. Scheme of dual electrospray ionization enhancement with DMSO solution supplied via a syringe pump. Created with BioRender.com

Syringe pump is turned on only for the time of protein elution in order to minimize amount of DMSO supplied to MS instrument. 
Table S1. Maximum and average charge states of studied proteins with and without flow from the second nebulizer

\begin{tabular}{|c|c|c|c|c|c|}
\hline Protein & Injection type & $\begin{array}{c}\text { Second } \\
\text { nebulizer }\end{array}$ & DMSO content & $\operatorname{Max} z$ & Average $\mathrm{z}$ \\
\hline $\mathrm{BSA}^{*}$ & Flow & Off & - & 43.6 & 45 \\
\hline BSA $^{*}$ & Flow & On & - & 46.1 & 45 \\
\hline $\mathrm{BSA}^{*}$ & Flow & On & $2.5 \%$ & 46.3 & 47 \\
\hline BSA $^{*}$ & Flow & On & $5 \%$ & 46.3 & 46 \\
\hline $\mathrm{BSA}^{*}$ & Flow & On & $10 \%$ & 47.5 & 47 \\
\hline $\mathrm{BSA}^{*}$ & Flow & On & $15 \%$ & 48.2 & 51 \\
\hline $\mathrm{BSA}^{*}$ & $\mathrm{LC}$ & Off & - & 46.5 & 49 \\
\hline $\mathrm{BSA}^{*}$ & $\mathrm{LC}$ & On & $10 \%$ & 55.1 & 55 \\
\hline $\mathrm{BSA}^{* *}$ & $\mathrm{LC}$ & Off & - & 49.2 & 52 \\
\hline $\mathrm{BSA}^{* *}$ & $\mathrm{LC}$ & On & $10 \%$ & 52.9 & 53 \\
\hline $\mathrm{BSA}^{* *}$ & $\mathrm{LC}$ & Off & $10 \%$ & \multirow{2}{*}{\multicolumn{2}{|c|}{$\begin{array}{l}\text { Protein signal suppressed } \\
\text { Protein signal suppressed }\end{array}$}} \\
\hline $\mathrm{BSA}^{* *}$ & $\mathrm{LC}$ & Off & $5 \%$ & & \\
\hline Lysozyme & $\mathrm{LC}$ & Off & - & 9.6 & 10 \\
\hline Lysozyme & $\mathrm{LC}$ & On & $10 \%$ & 12.8 & 13 \\
\hline Amelogenin & $\mathrm{LC}$ & Off & - & 15.6 & 16 \\
\hline Amelogenin & $\mathrm{LC}$ & On & $10 \%$ & 13.9 & 14 \\
\hline Thioreductase & $\mathrm{LC}$ & Off & - & 30.6 & 32 \\
\hline Thioreductase & $\mathrm{LC}$ & On & $10 \%$ & 31.4 & 32 \\
\hline $\mathrm{A}_{2 \mathrm{~A}}$ & $\mathrm{LC}$ & Off & - & 40.7 & 43 \\
\hline $\mathrm{A}_{2 \mathrm{~A}}$ & $\mathrm{LC}$ & On & $10 \%$ & 39.8 & 42 \\
\hline $\mathrm{KOR}^{*}$ & $\mathrm{LC}$ & Off & - & 51.4 & 52 \\
\hline $\mathrm{KOR}^{*}$ & $\mathrm{LC}$ & On & $10 \%$ & 51.2 & 53 \\
\hline $\mathrm{KOR}^{* *}$ & $\mathrm{LC}$ & Off & - & 47.6 & 48 \\
\hline $\mathrm{KOR}^{* *}$ & $\mathrm{LC}$ & On & $5 \%$ & 48.7 & 52 \\
\hline $\mathrm{KOR}^{* *}$ & $\mathrm{LC}$ & Off & $5 \%$ & 55 & 57 \\
\hline
\end{tabular}

* and ${ }^{* *}$ marks different batches of protein 
Optimization of the flow rates
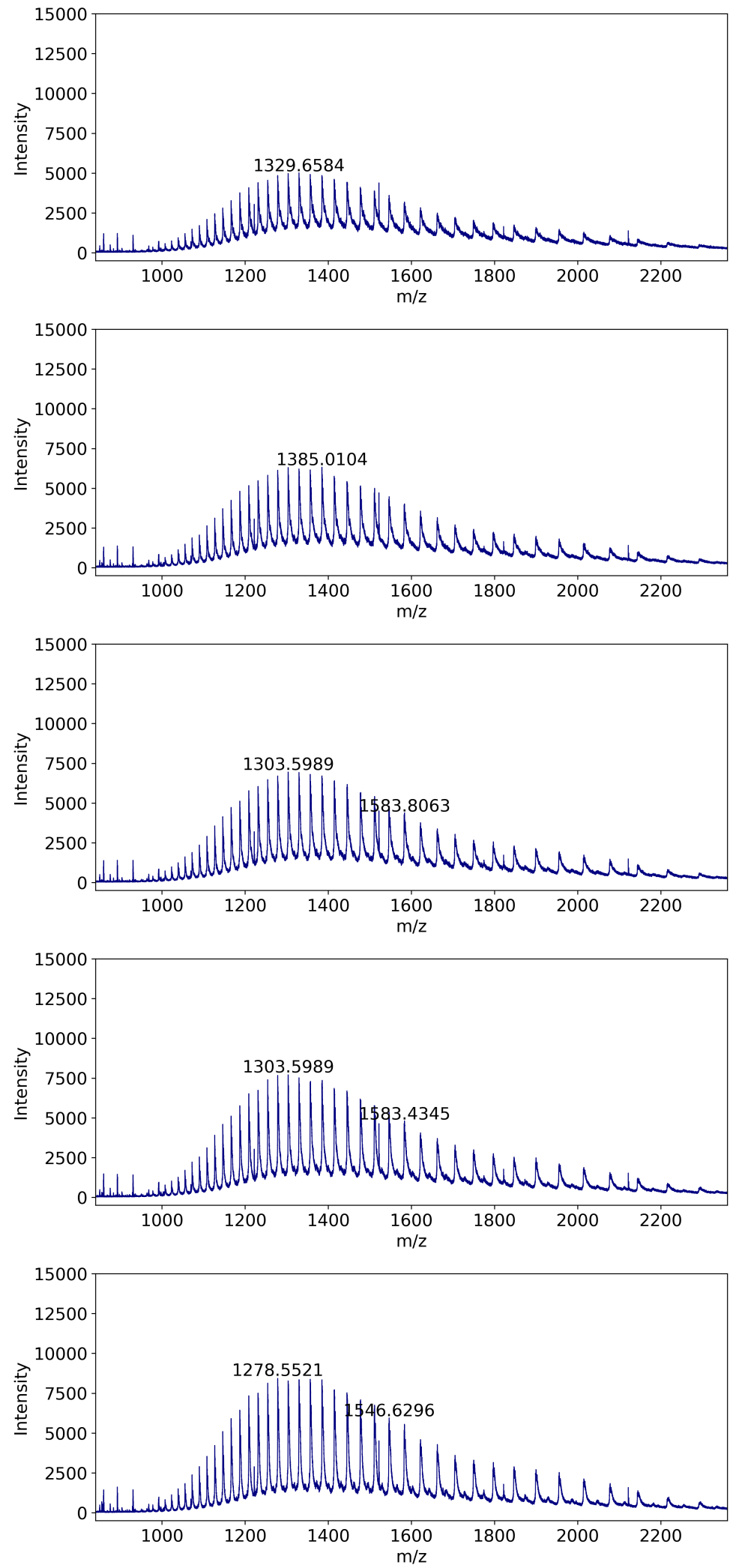

Figure S3. Mass spectra (5 replicas) of BSA at $50 \mu \mathrm{L} / \mathrm{min}$ flow. 

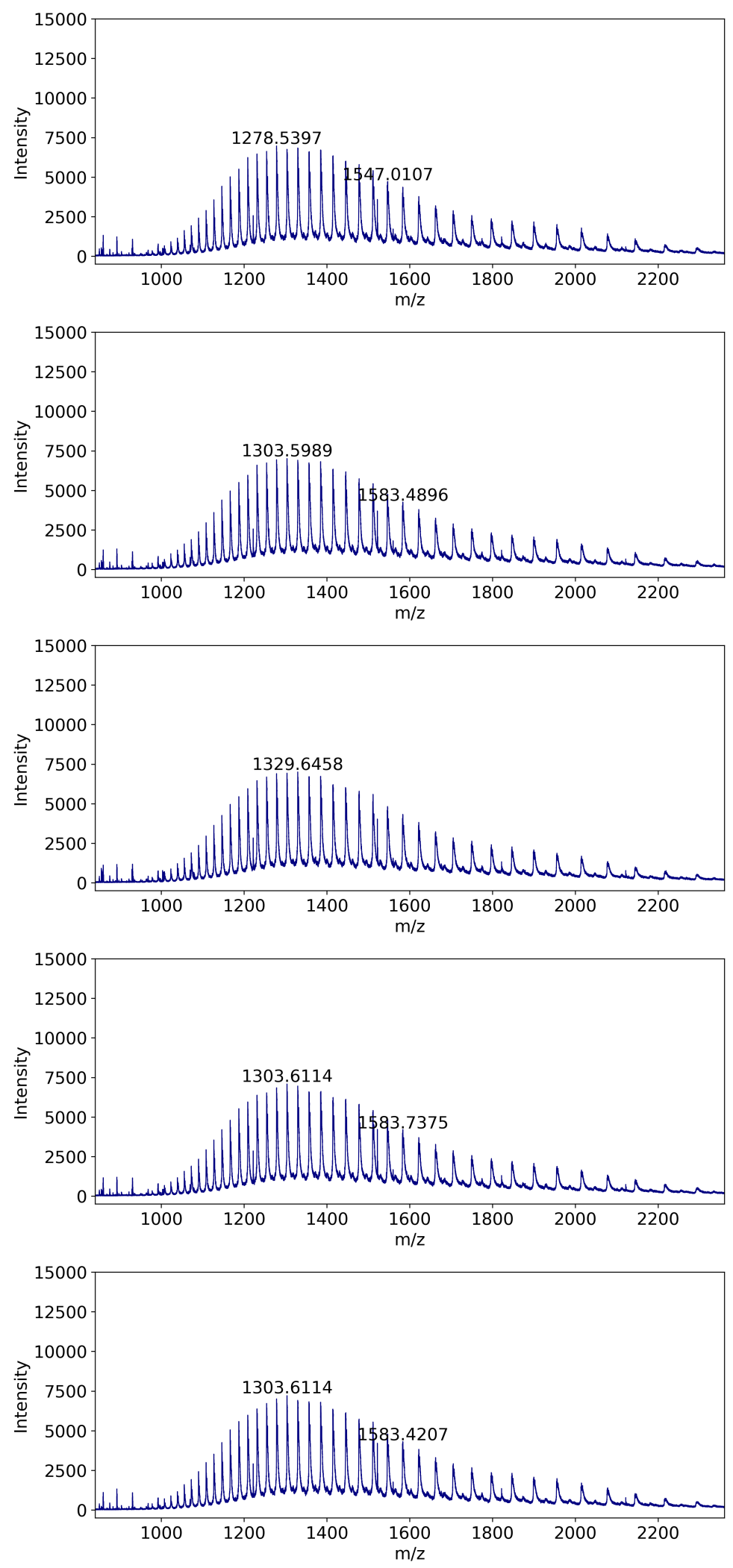

Figure S4. Mass spectra (5 replicas) of BSA at $50 \mu \mathrm{L} / \mathrm{min}$ flow with $100 \mu \mathrm{L} / \mathrm{min}$ water sprayed from the second nebulizer. 

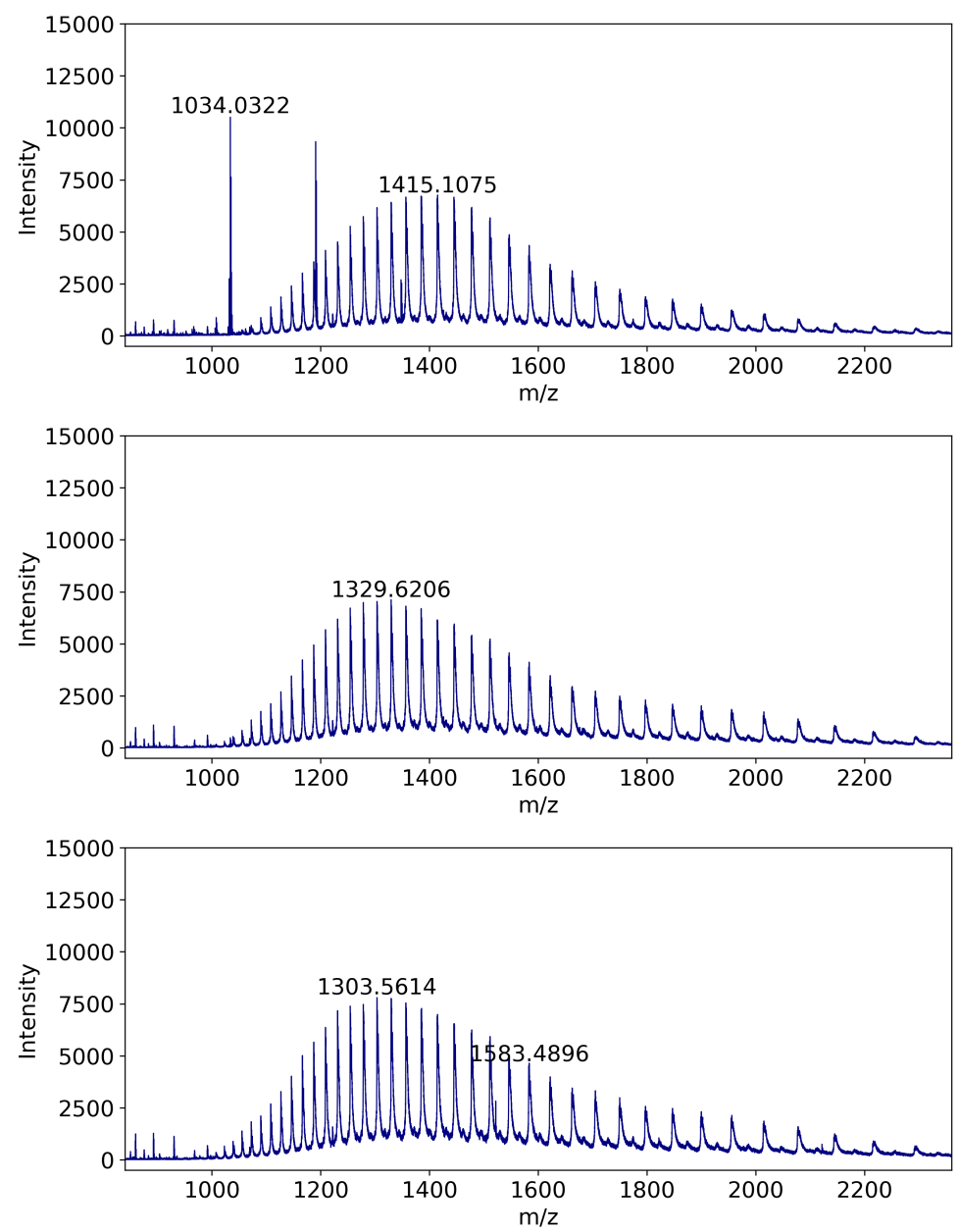

Figure S5. Mass spectra (3 replicas) of BSA at $50 \mu \mathrm{L} / \mathrm{min}$ flow with $100 \mu \mathrm{L} / \mathrm{min} 5 \%$ DMSO sprayed from the second nebulizer. 

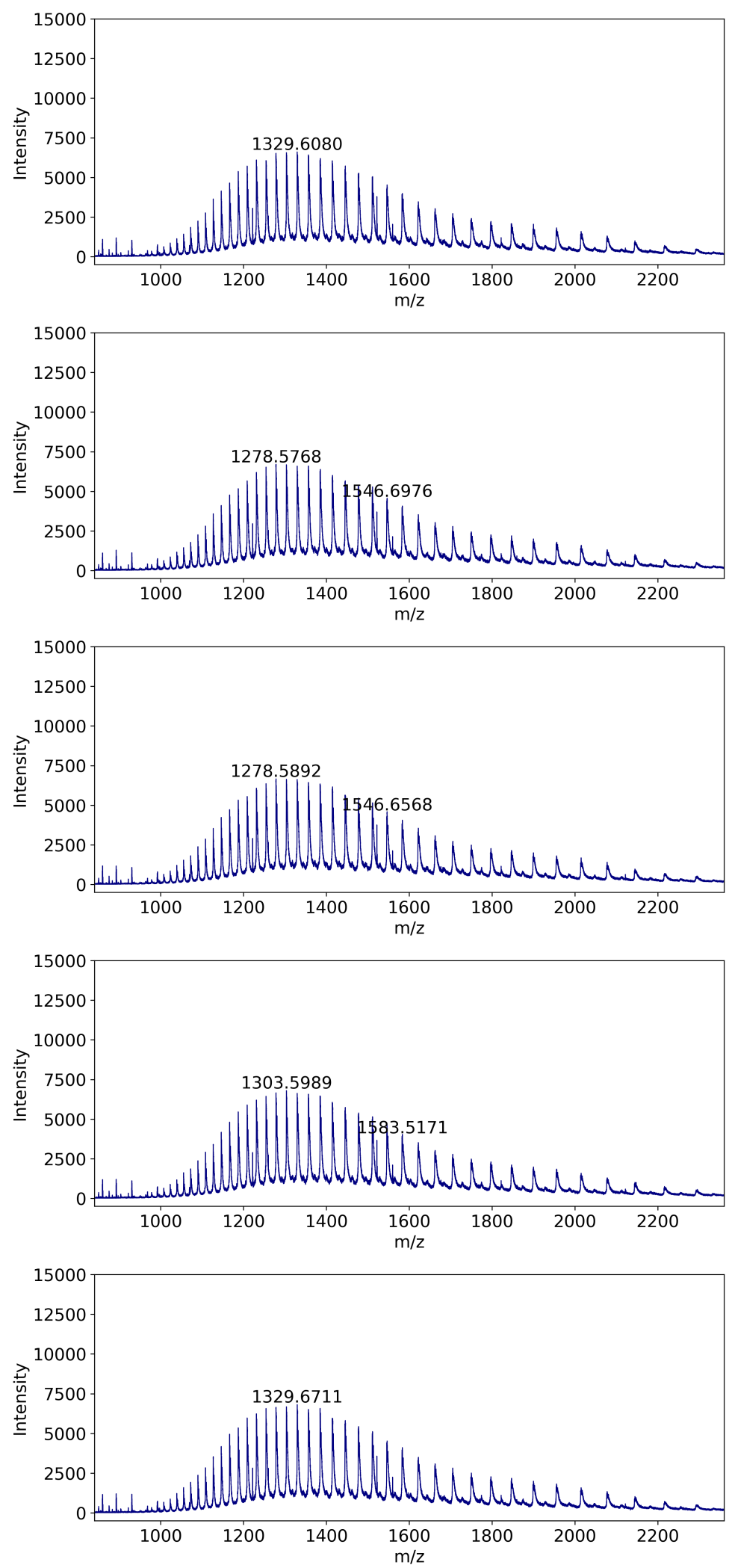

Figure S6. Mass spectra (5 replicas) of BSA at $50 \mu \mathrm{L} / \mathrm{min}$ flow with $200 \mu \mathrm{L} / \mathrm{min}$ water sprayed from the second nebulizer. 

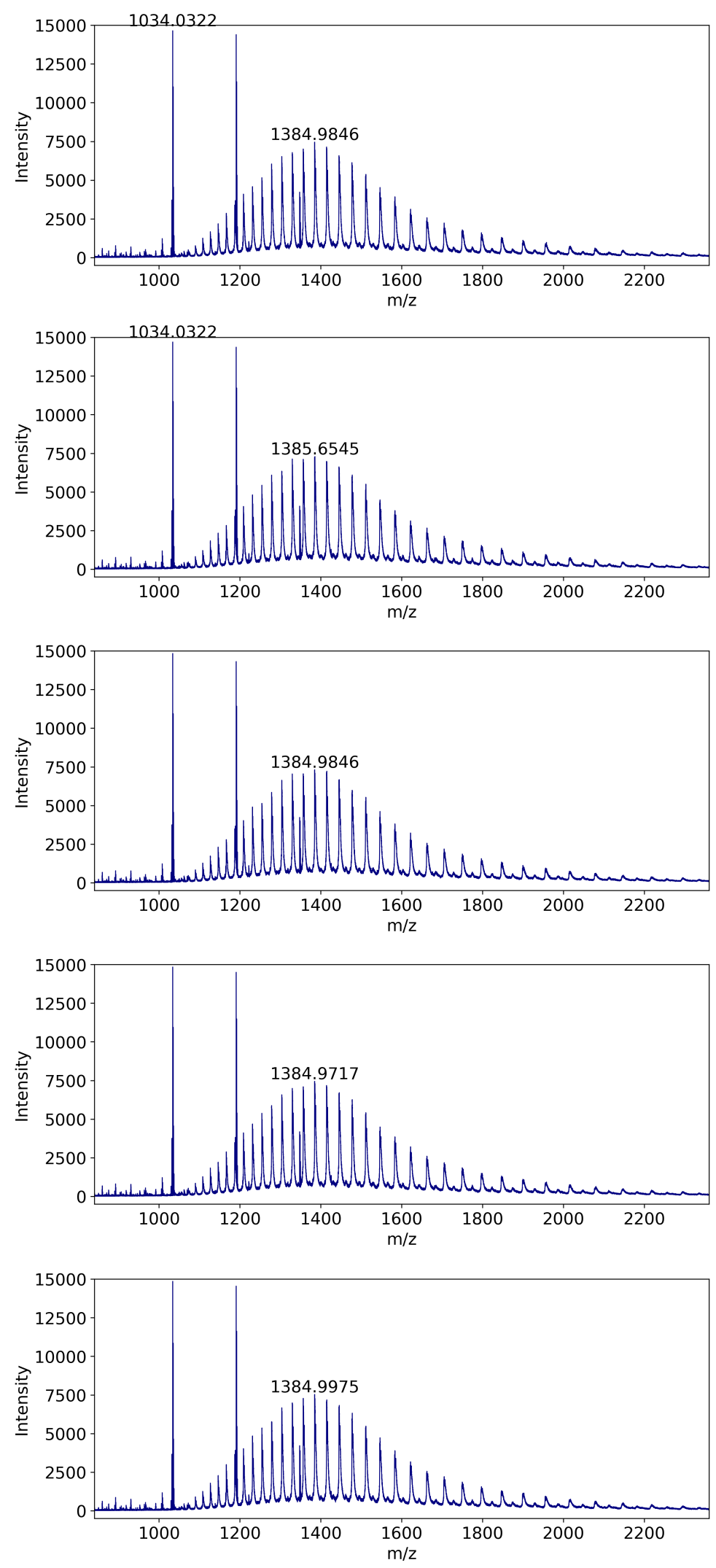

Figure S7. Mass spectra (5 replicas) of BSA at $50 \mu \mathrm{L} / \mathrm{min}$ flow with $200 \mu \mathrm{L} / \mathrm{min} 5 \%$ DMSO sprayed from the second nebulizer. 

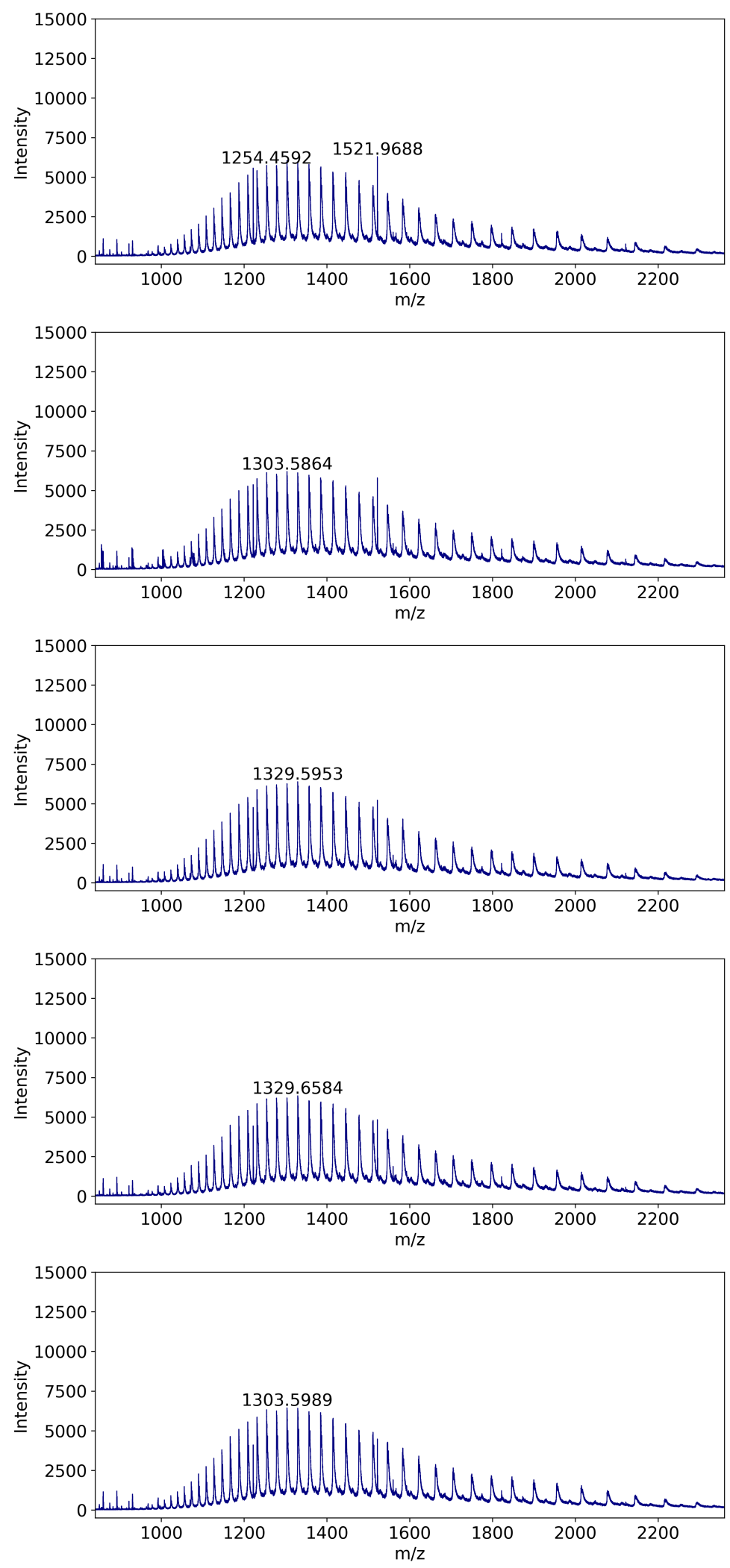

Figure S8. Mass spectra (5 replicas) of BSA at $50 \mu \mathrm{L} / \mathrm{min}$ flow with $300 \mu \mathrm{L} / \mathrm{min}$ water sprayed from the second nebulizer. 

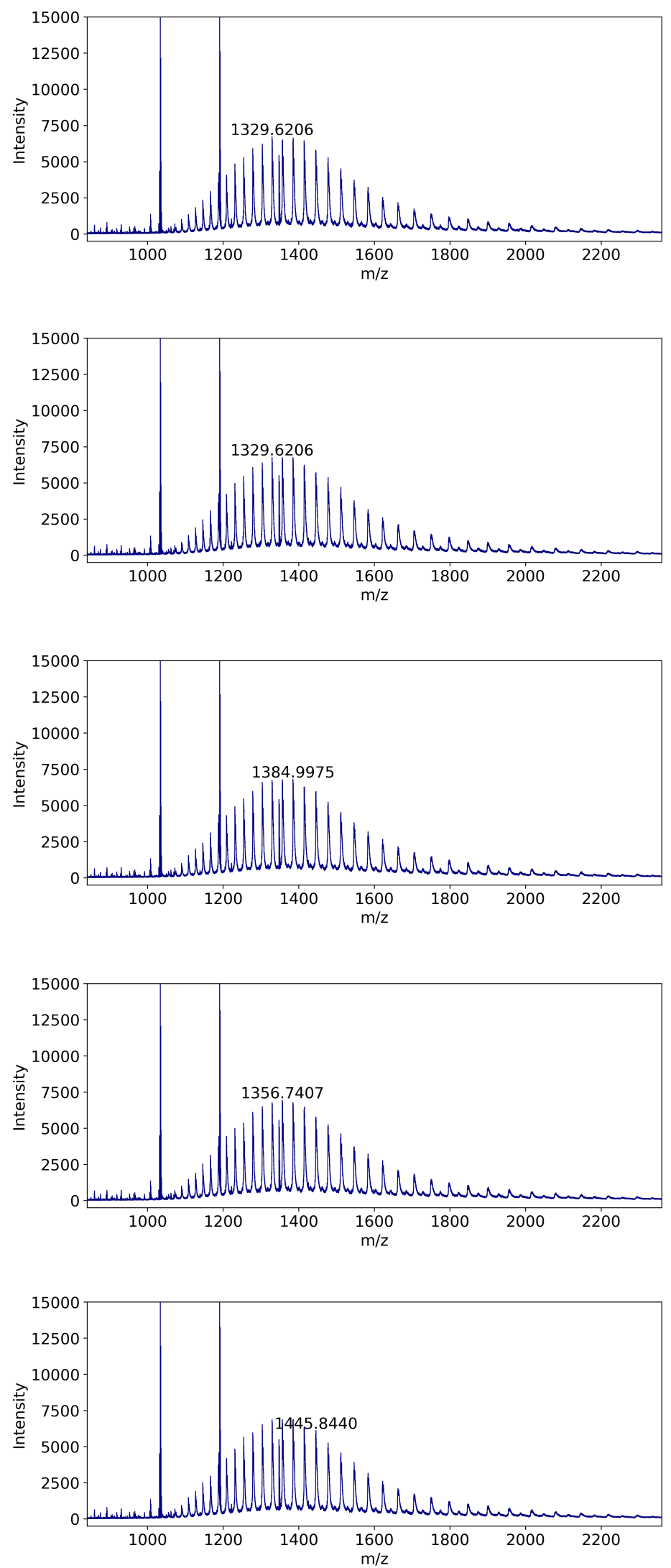

Figure S9. Mass spectra (5 replicas) of BSA at $50 \mu \mathrm{L} / \mathrm{min}$ flow with $300 \mu \mathrm{L} / \mathrm{min} 5 \%$ DMSO sprayed from the second nebulizer. 


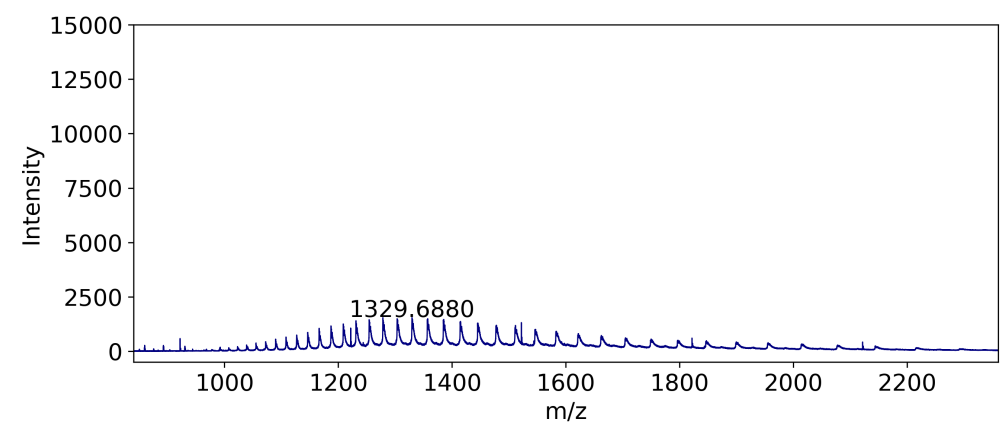

Figure S10. Mass spectrum of BSA at $5 \mu \mathrm{L} / \mathrm{min}$ flow.

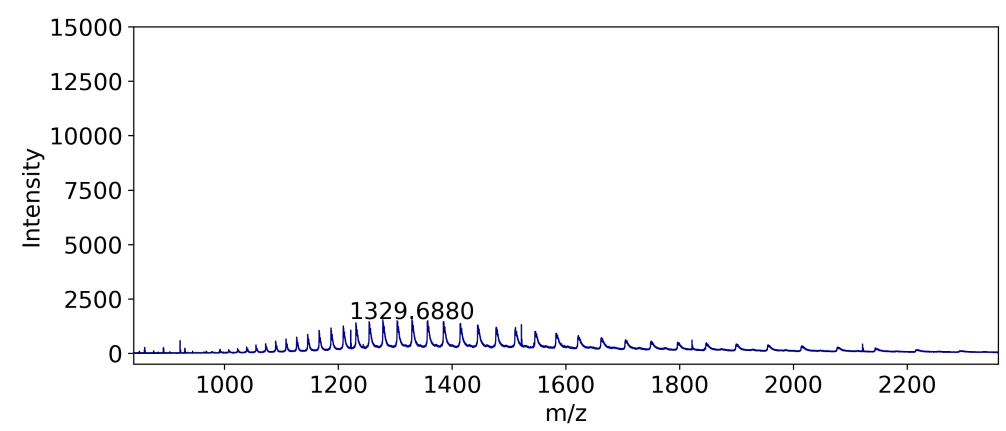

Figure S11. Mass spectrum of BSA at $5 \mu \mathrm{L} / \mathrm{min}$ flow with $300 \mu \mathrm{L} / \mathrm{min}$ water sprayed from the second nebulizer.

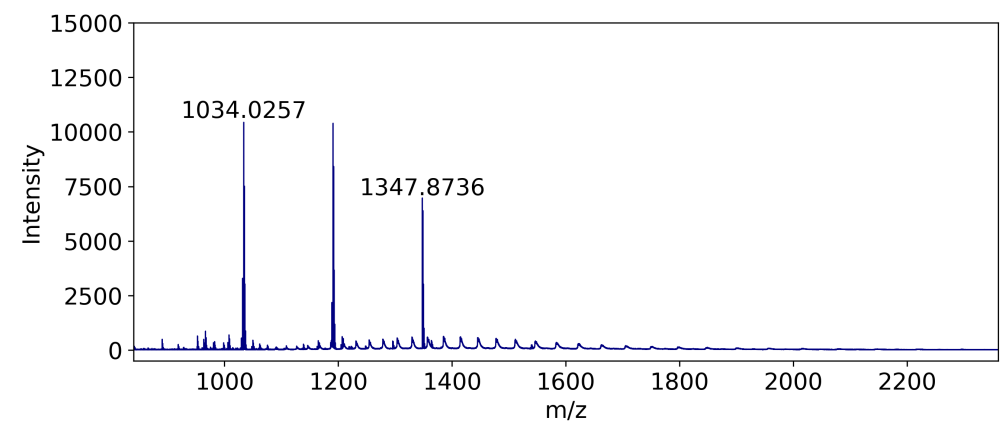

Figure S12. Mass spectrum of BSA at $5 \mu \mathrm{L} /$ min flow with $300 \mu \mathrm{L} / \mathrm{min} 5 \%$ DMSO sprayed from the second nebulizer. 


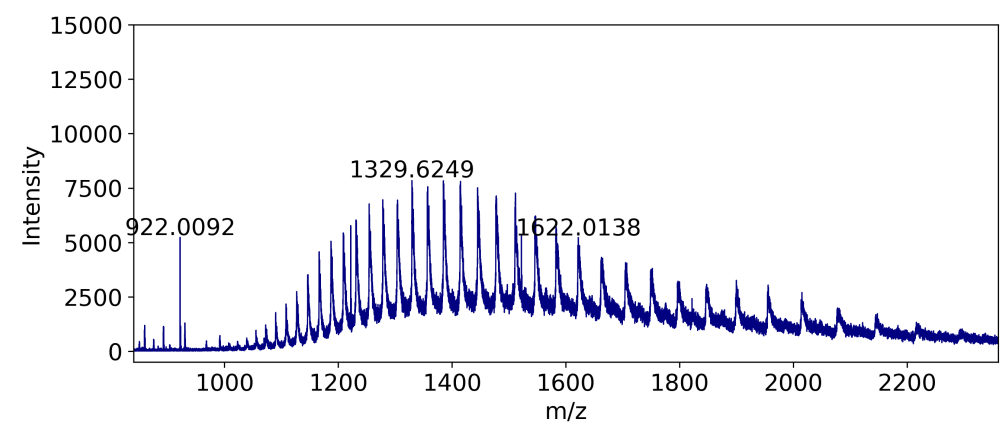

Figure S13. Mass spectrum of BSA at $500 \mu \mathrm{L} / \mathrm{min}$ flow.

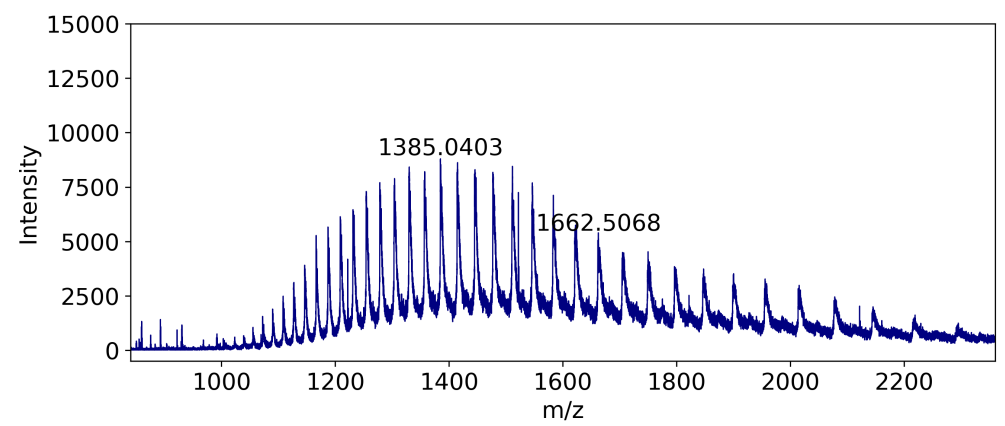

Figure S14. Mass spectrum of BSA at $500 \mu \mathrm{L} / \mathrm{min}$ flow with $300 \mu \mathrm{L} / \mathrm{min}$ water sprayed from the second nebulizer.

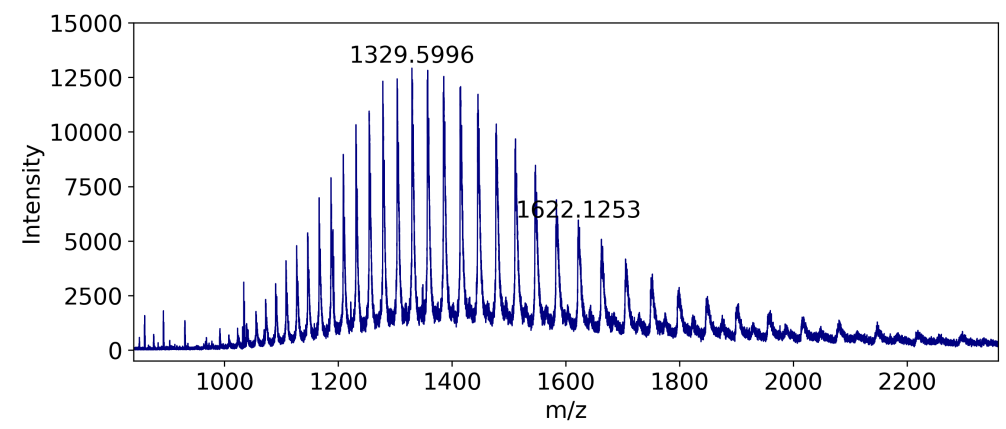

Figure S15. Mass spectrum of BSA at $500 \mu \mathrm{L} /$ min flow with $300 \mu \mathrm{L} / \mathrm{min} 5 \%$ DMSO sprayed from the second nebulizer. 
Optimization of DMSO content
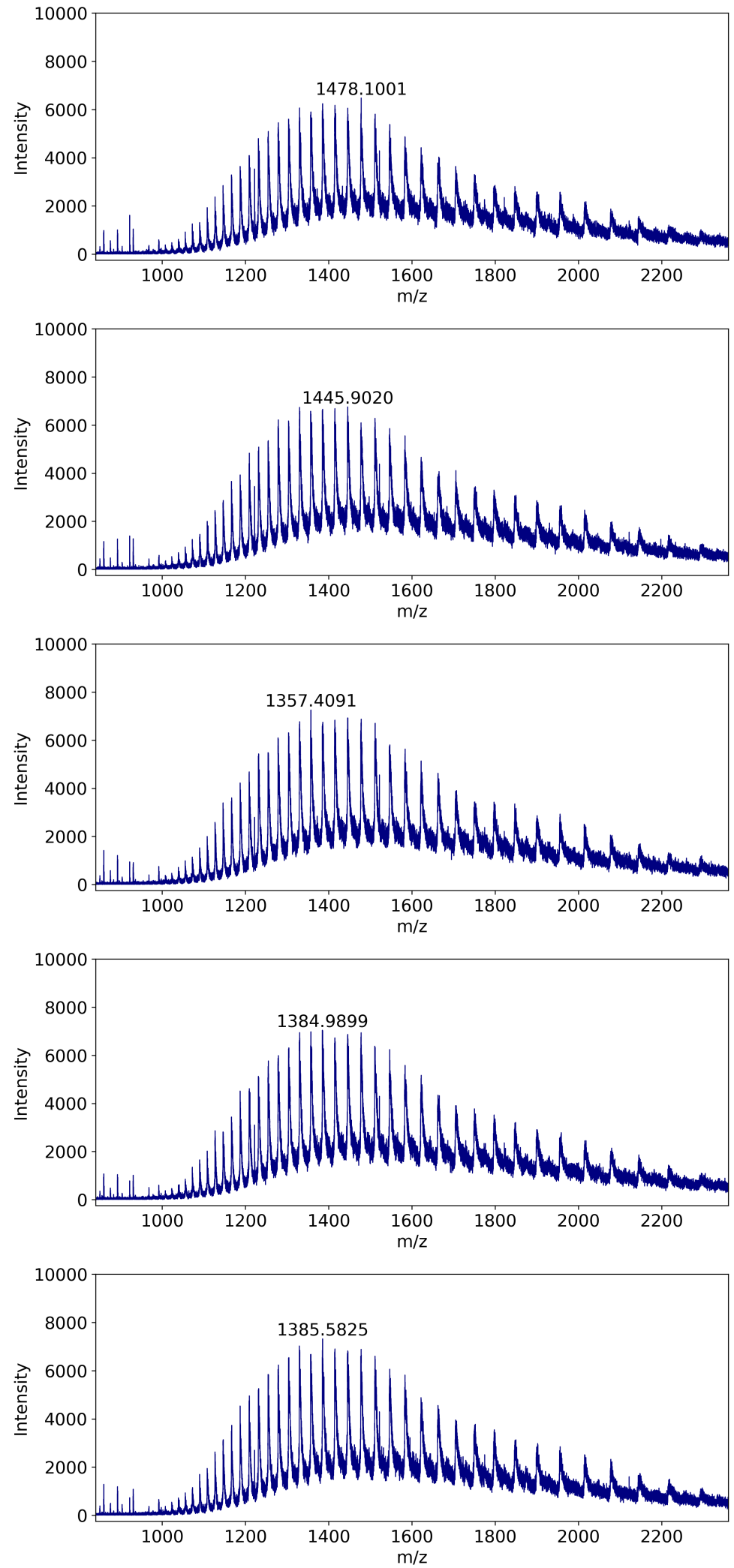

Figure S16. Mass spectrum of BSA at $500 \mu \mathrm{L} / \mathrm{min}$ flow. 

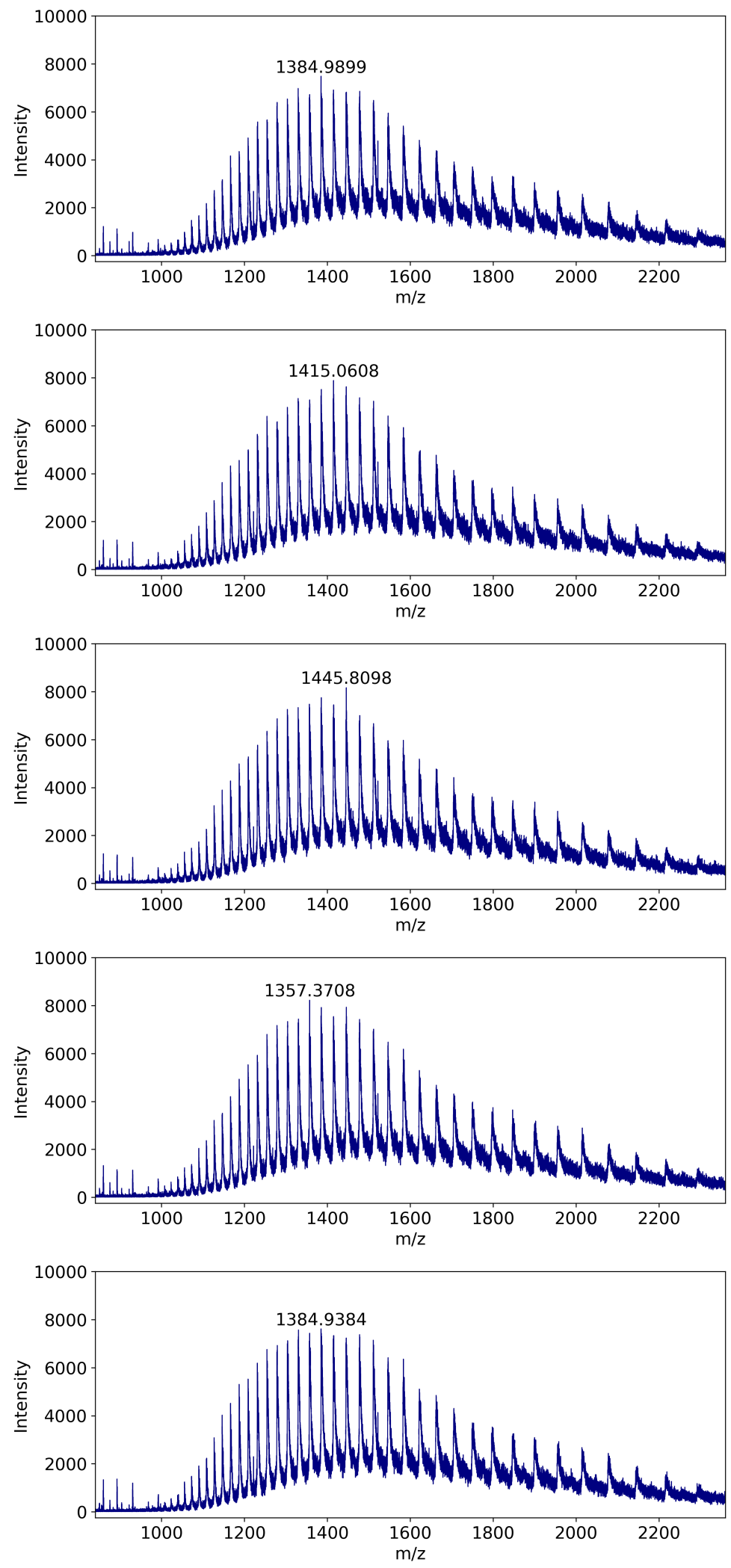

Figure S17. Mass spectrum of BSA at $500 \mu \mathrm{L} / \mathrm{min}$ flow with $300 \mu \mathrm{L} / \mathrm{min}$ water sprayed from the second nebulizer. 

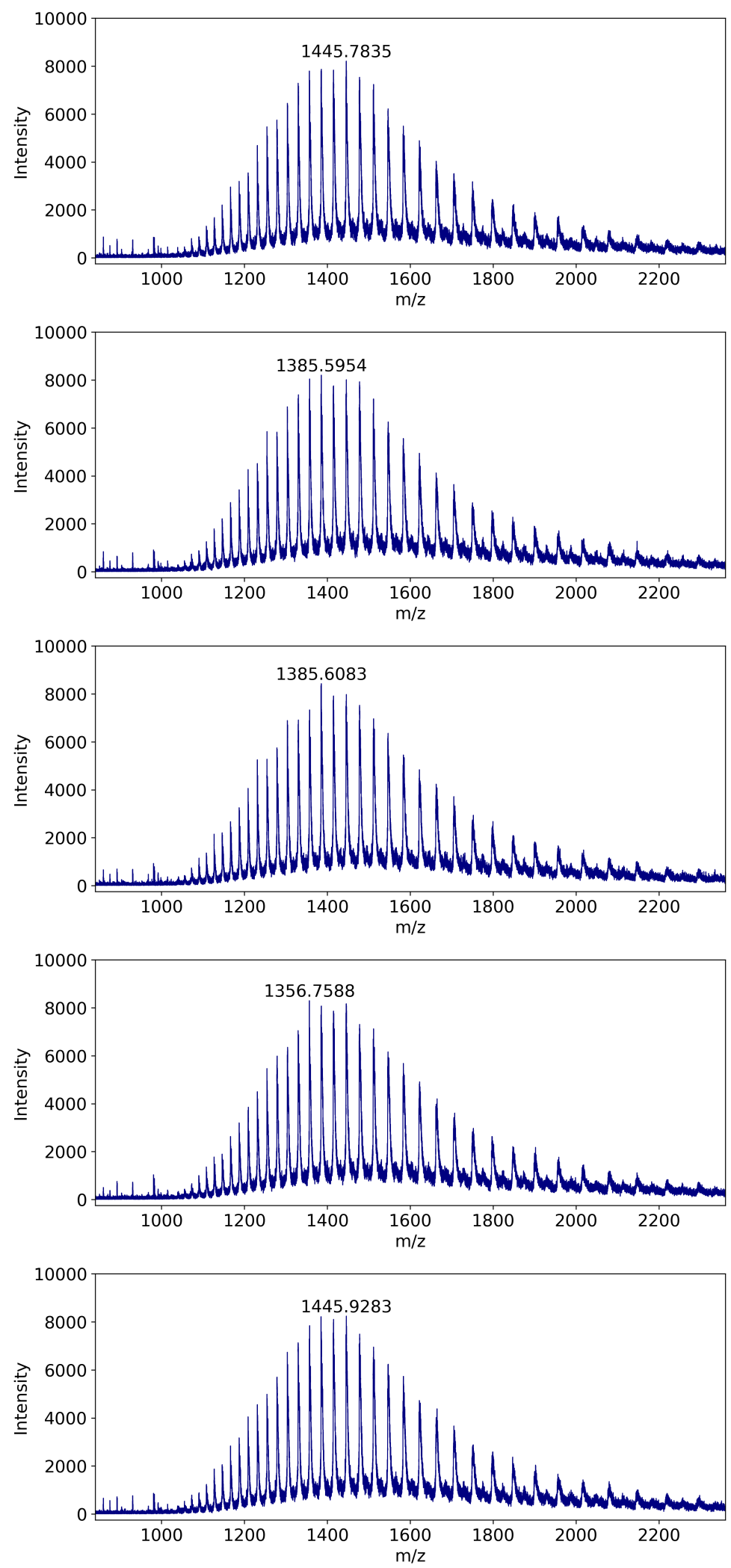

Figure S18. Mass spectrum of BSA at $500 \mu \mathrm{L} / \mathrm{min}$ flow with $300 \mu \mathrm{L} / \mathrm{min} 2.5 \%$ DMSO sprayed from the second nebulizer. 

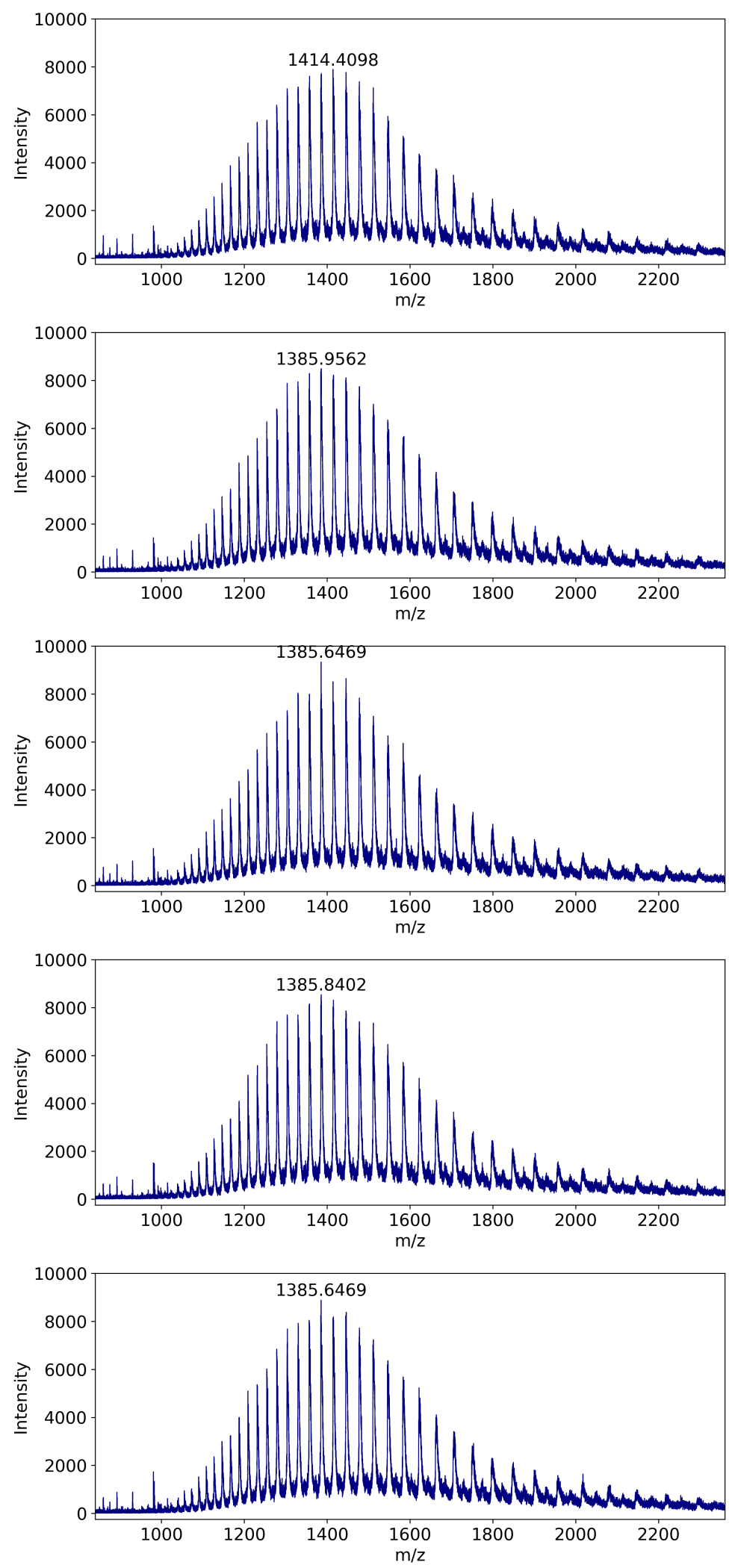

Figure S19. Mass spectrum of BSA at $500 \mu \mathrm{L} / \mathrm{min}$ flow with $300 \mu \mathrm{L} / \mathrm{min} 5 \%$ DMSO sprayed from the second nebulizer. 

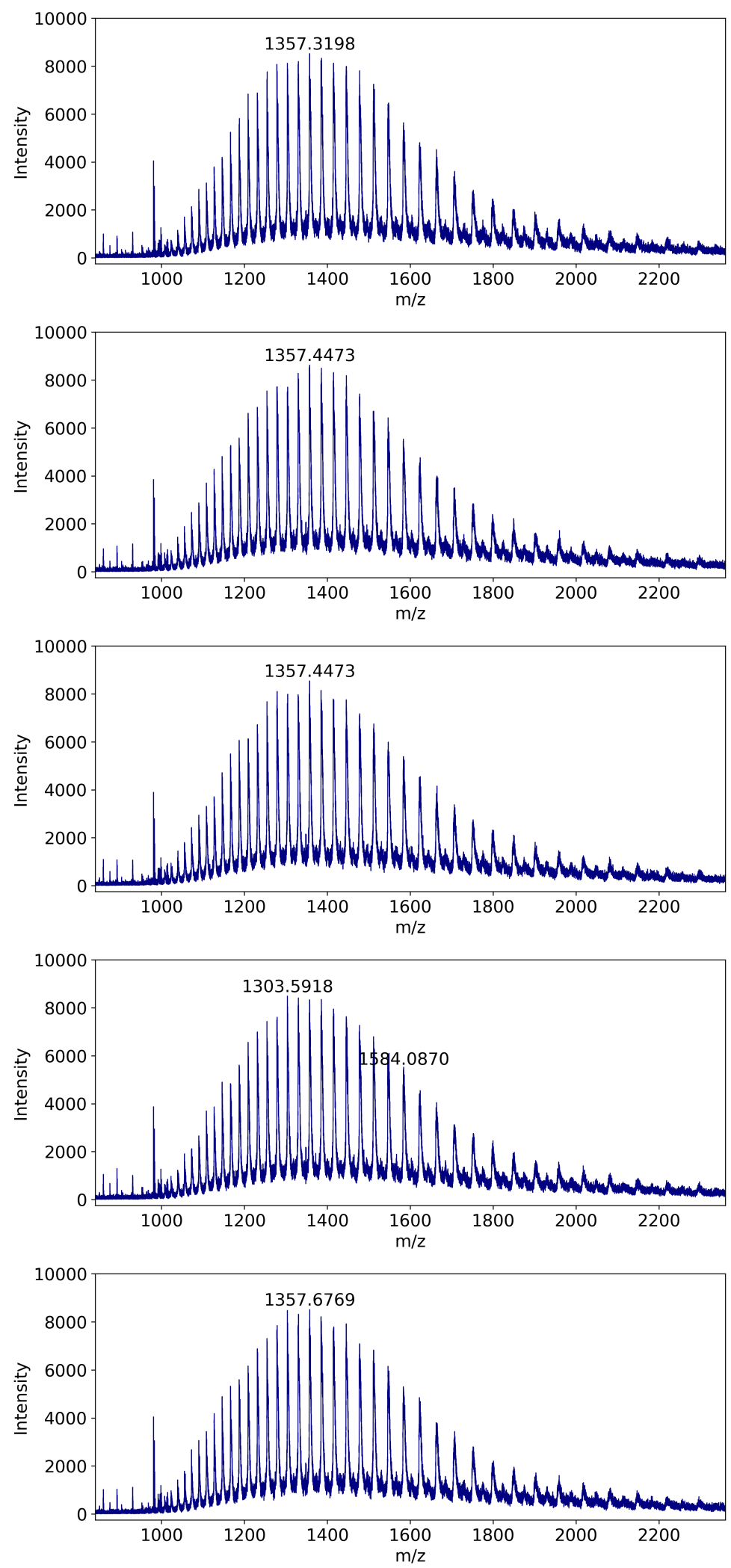

Figure S20. Mass spectrum of BSA at $500 \mu \mathrm{L} / \mathrm{min}$ flow with $300 \mu \mathrm{L} / \mathrm{min} 10 \%$ DMSO sprayed from the second nebulizer. 

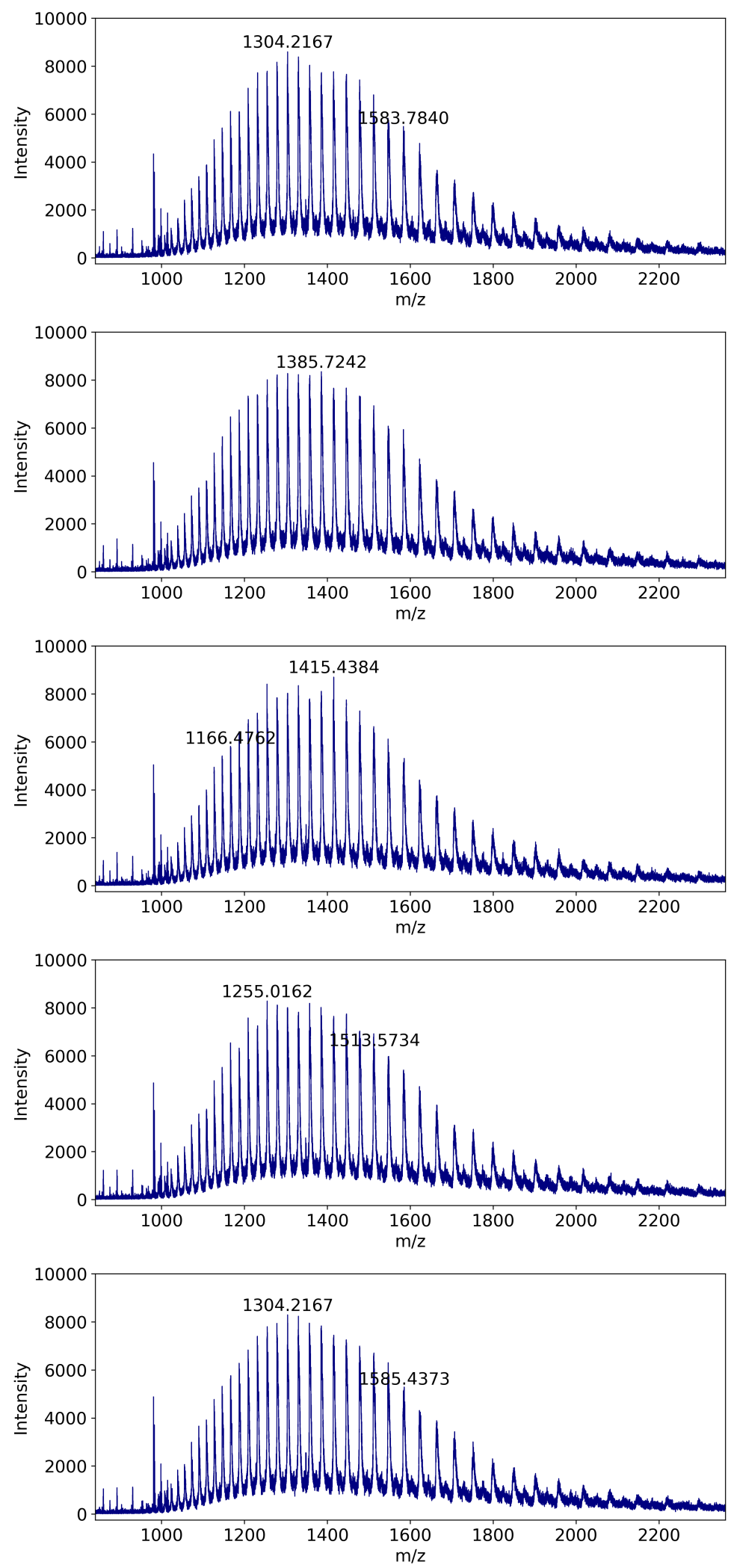

Figure S21. Mass spectrum of BSA at $500 \mu \mathrm{L} / \mathrm{min}$ flow with $300 \mu \mathrm{L} / \mathrm{min} 15 \%$ DMSO sprayed from the second nebulizer. 
Verification of DMSO content with lysozyme
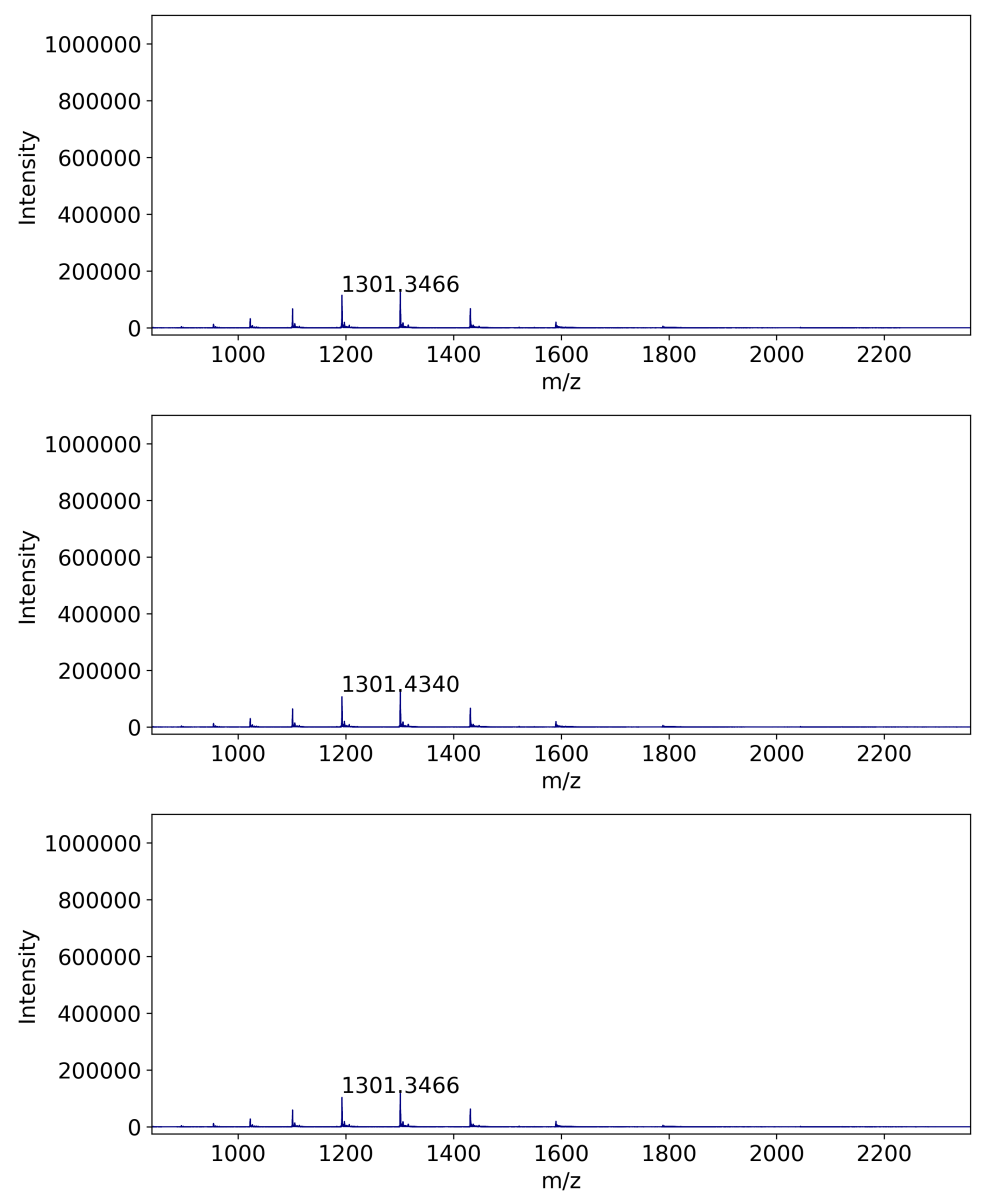

Figure S22. Mass spectrum of BSA at $500 \mu \mathrm{L} / \mathrm{min}$ flow. 

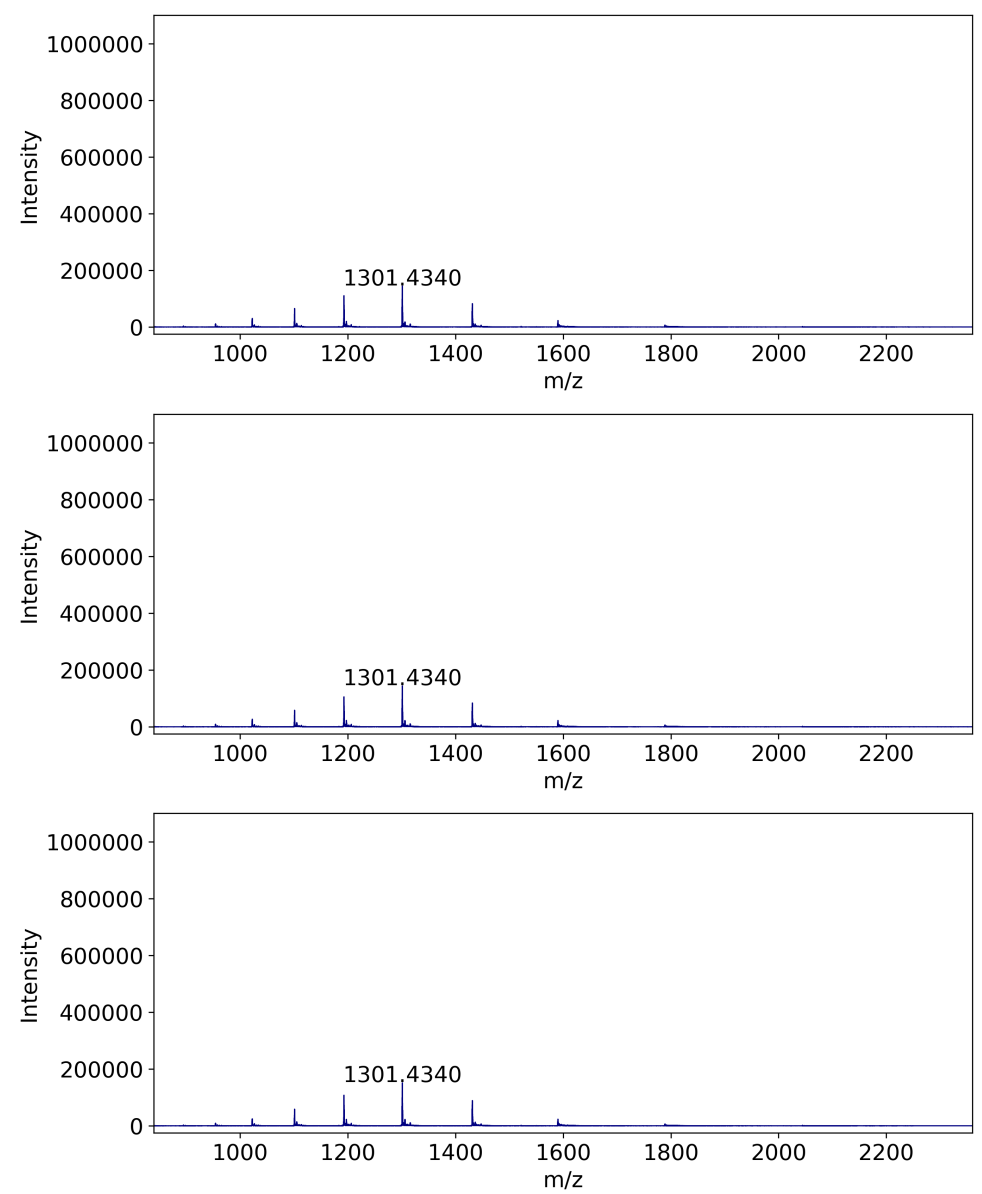

Figure S23. Mass spectrum of BSA at $500 \mu \mathrm{L} / \mathrm{min}$ flow with $300 \mu \mathrm{L} / \mathrm{min}$ water sprayed from the second nebulizer. 

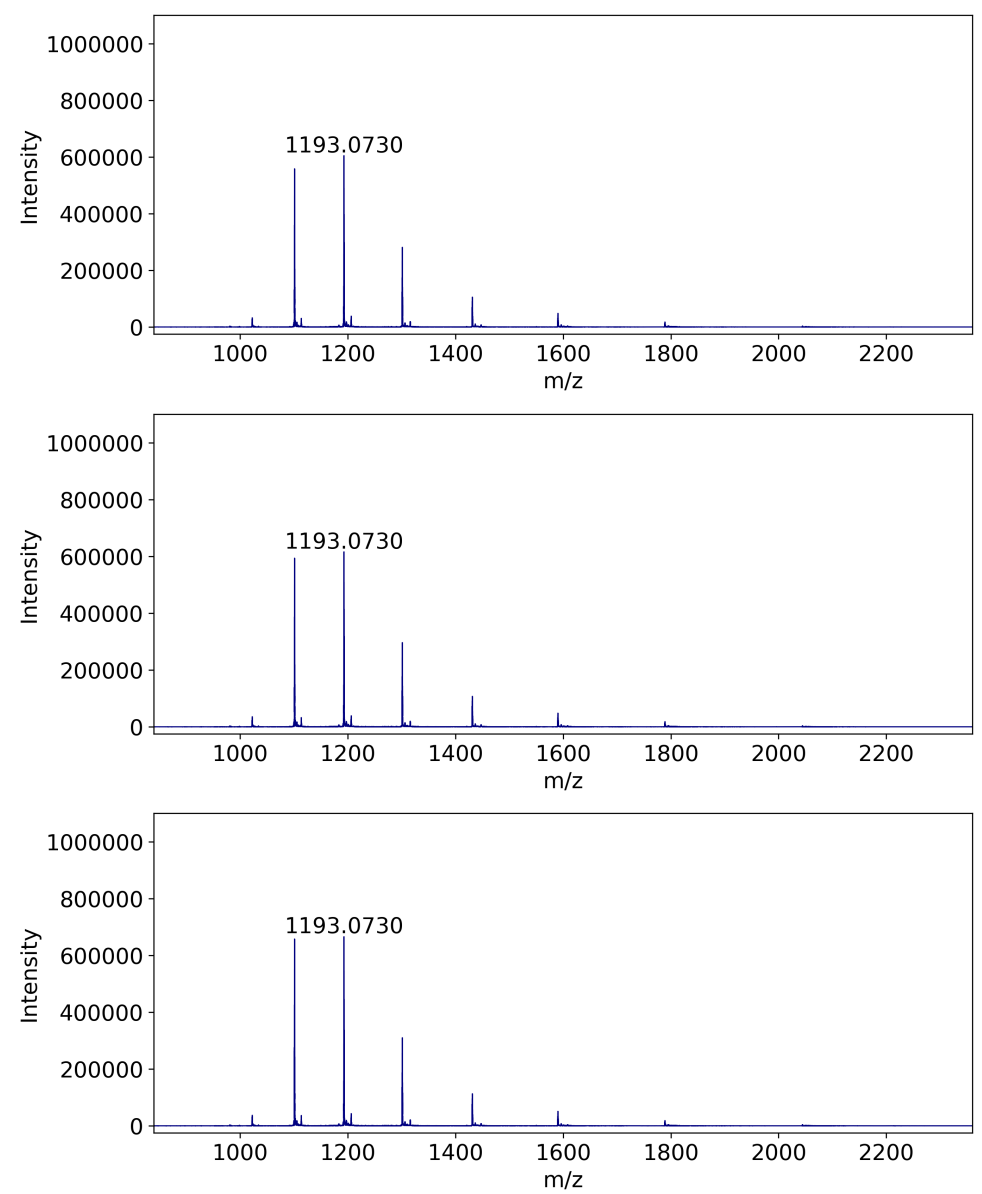

Figure S24. Mass spectrum of BSA at $500 \mu \mathrm{L} / \mathrm{min}$ flow with $300 \mu \mathrm{L} / \mathrm{min} 5 \%$ DMSO sprayed from the second nebulizer. 

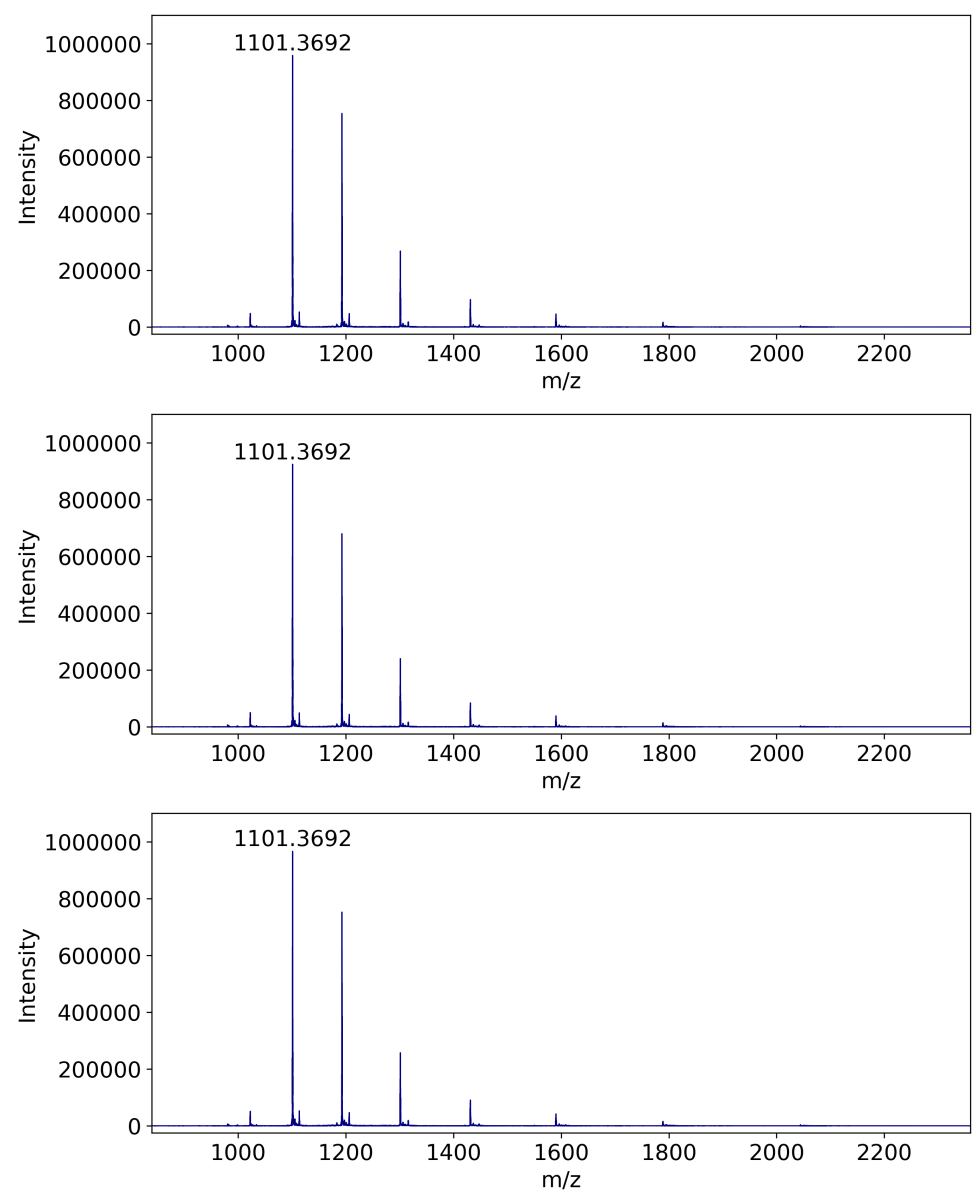

Figure S25. Mass spectrum of BSA at $500 \mu \mathrm{L} / \mathrm{min}$ flow with $300 \mu \mathrm{L} / \mathrm{min} 10 \%$ DMSO sprayed from the second nebulizer. 
HPLC analysis of intact proteins

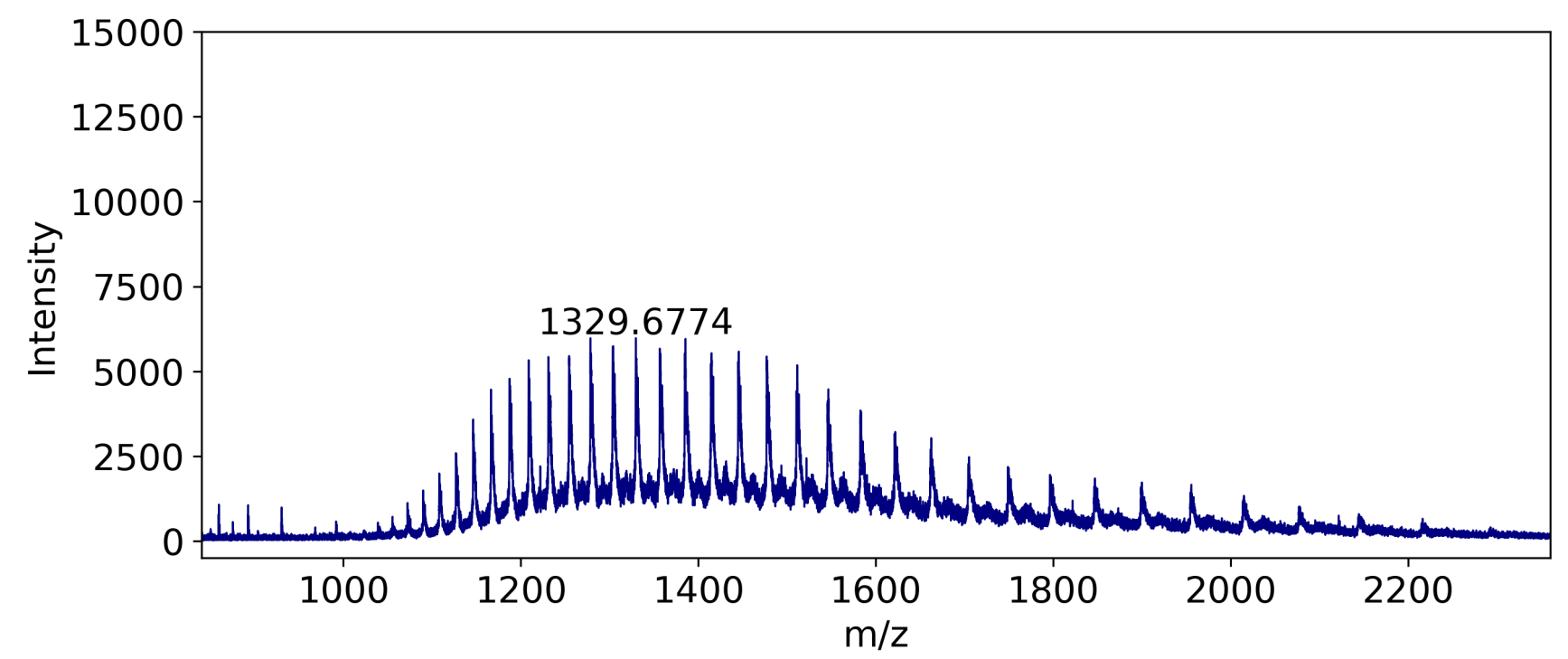

Figure S26. Mass spectrum of BSA at $500 \mu \mathrm{L} / \mathrm{min}$ flow.

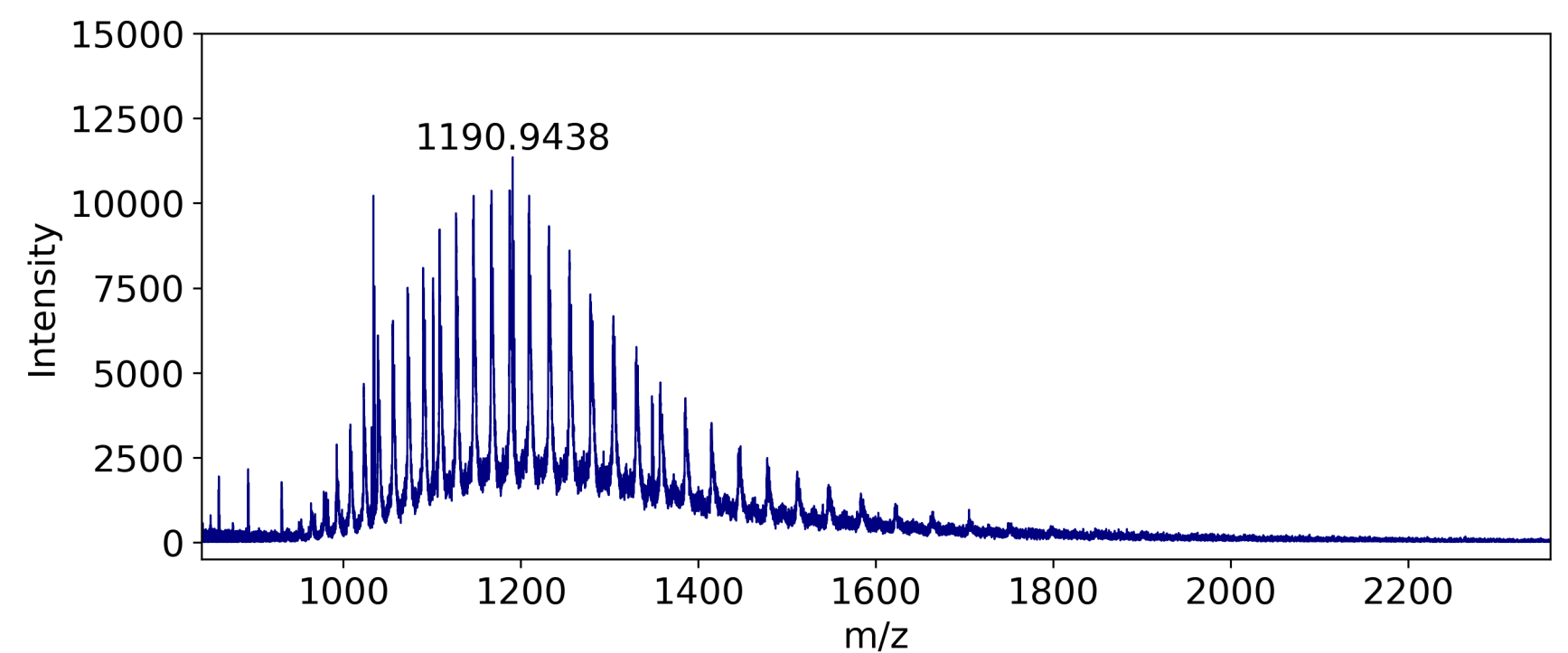

Figure S27. Mass spectrum of BSA at $500 \mu \mathrm{L} /$ min flow with $300 \mu \mathrm{L} / \mathrm{min} 10 \%$ DMSO sprayed from the second nebulizer. 


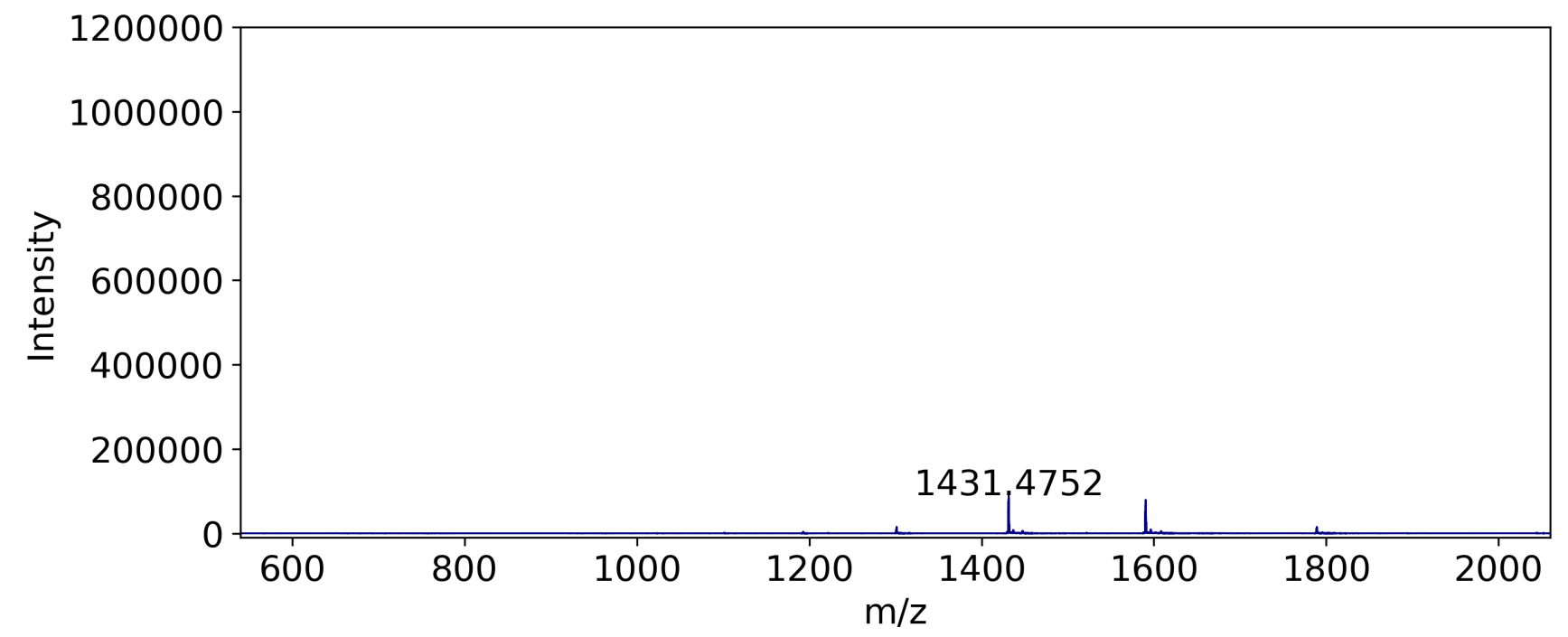

Figure S28. Mass spectrum of lysozyme at $500 \mu \mathrm{L} / \mathrm{min}$ flow.

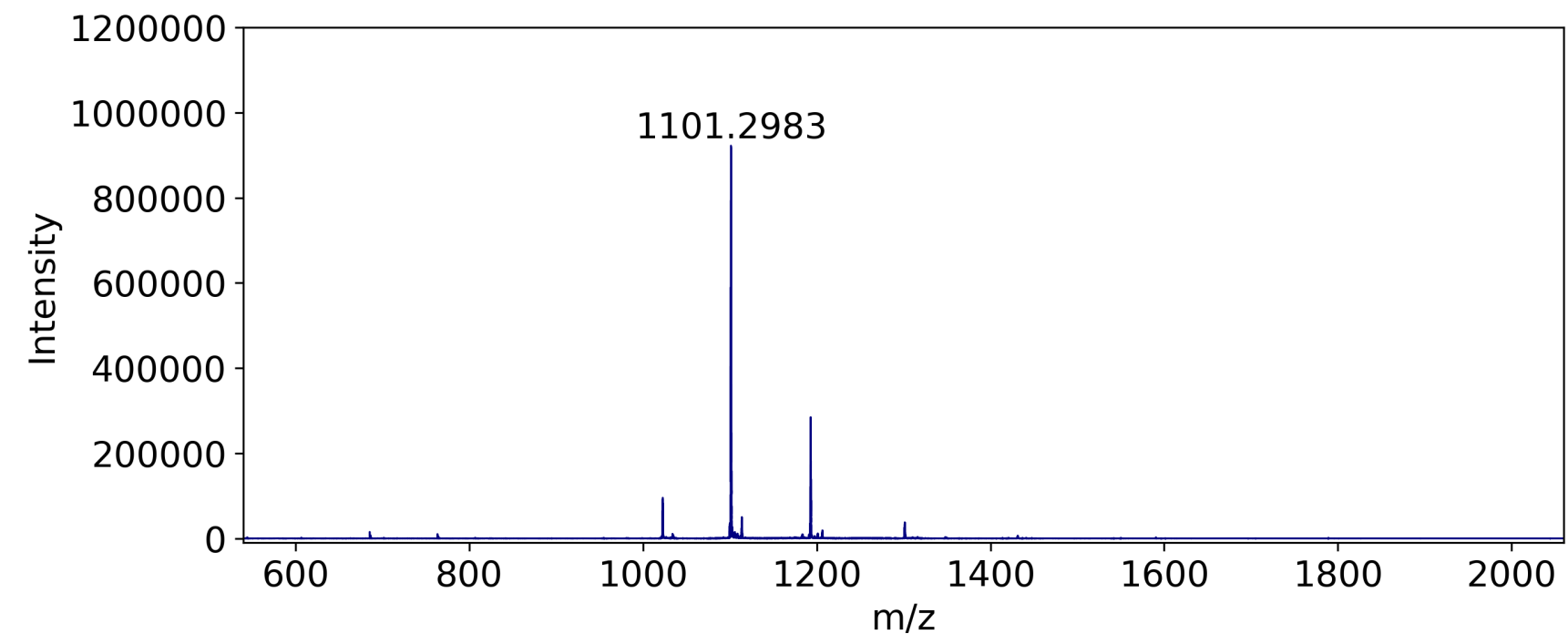

Figure S29. Mass spectrum of lysozyme at $500 \mu \mathrm{L} / \mathrm{min}$ flow with $300 \mu \mathrm{L} / \mathrm{min} 10 \%$ DMSO sprayed from the second nebulizer. 


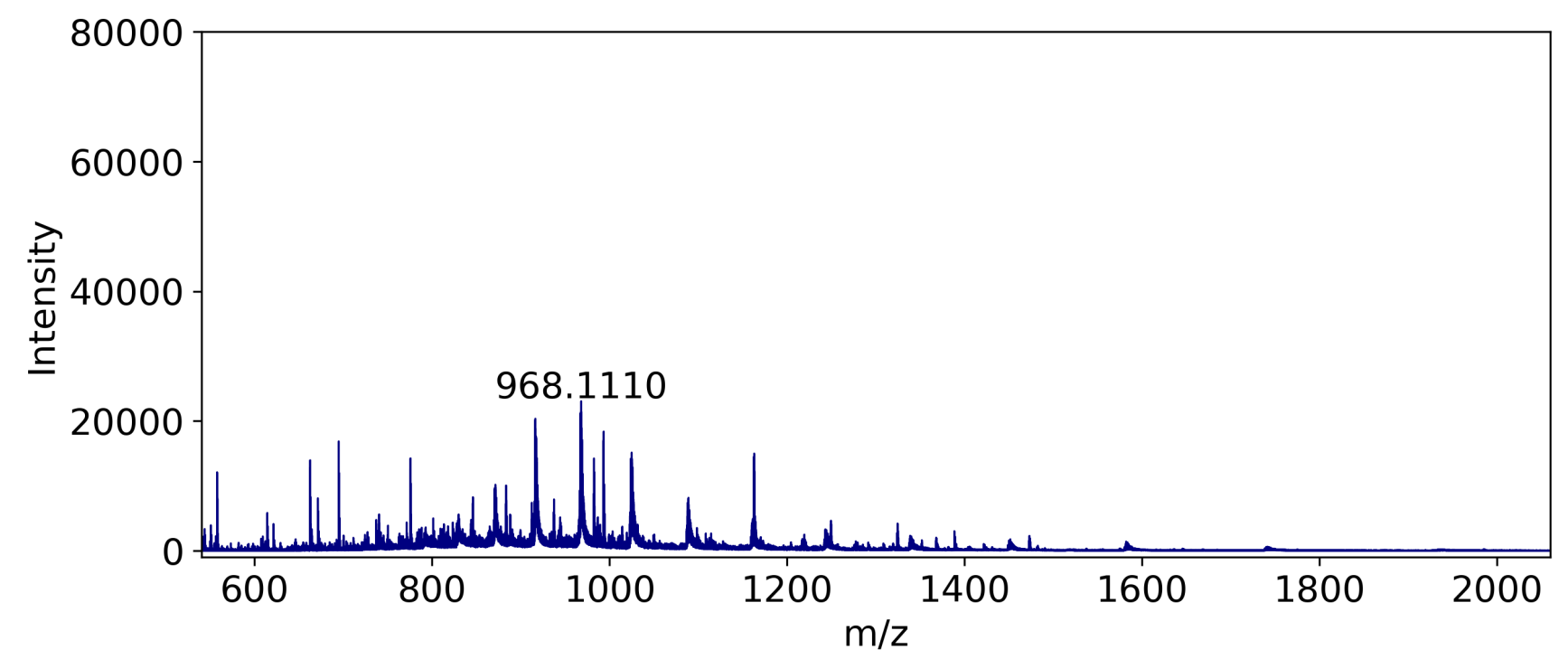

Figure S30. Mass spectrum of amelogenin at $500 \mu \mathrm{L} / \mathrm{min}$ flow.

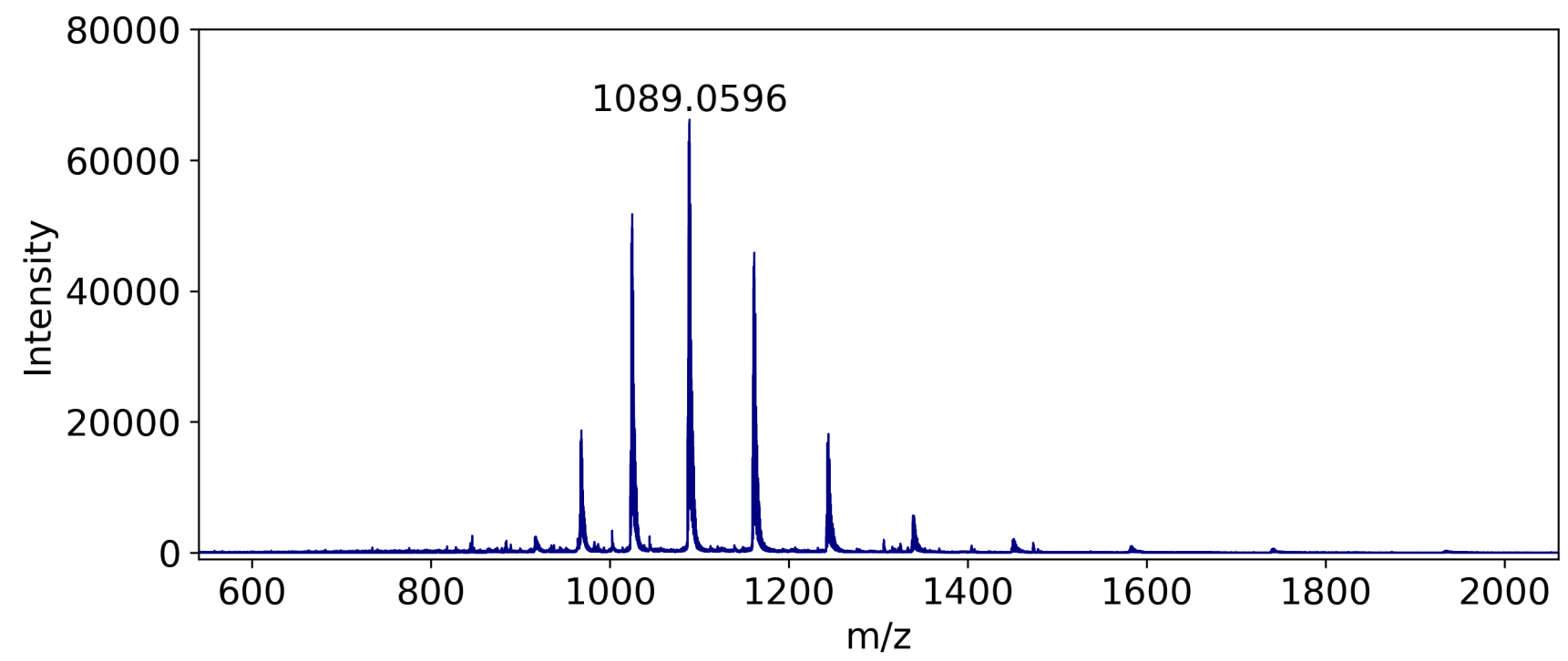

Figure S31. Mass spectrum of amelogenin at $500 \mu \mathrm{L} / \mathrm{min}$ flow with $300 \mu \mathrm{L} / \mathrm{min} 10 \%$ DMSO sprayed from the second nebulizer. 


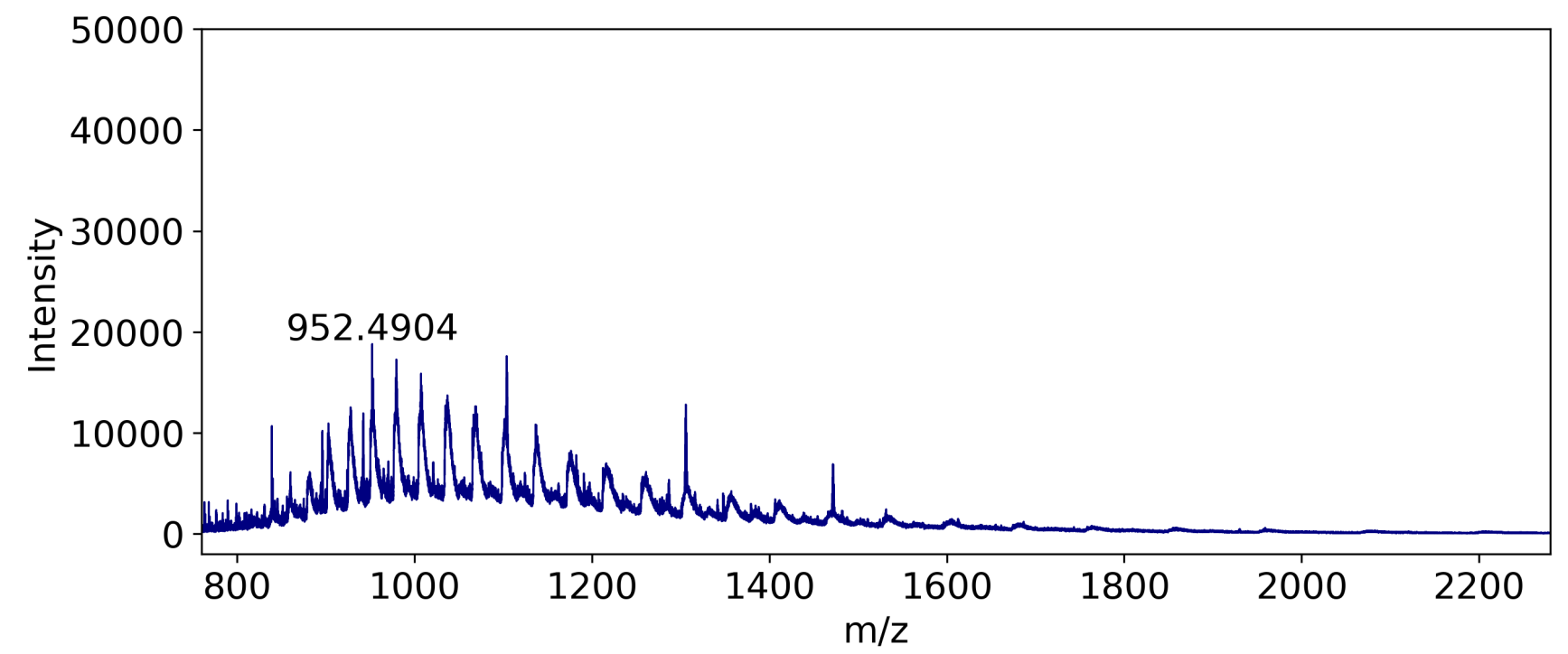

Figure S32. Mass spectrum of thioredoxin reductase at $500 \mu \mathrm{L} / \mathrm{min}$ flow.

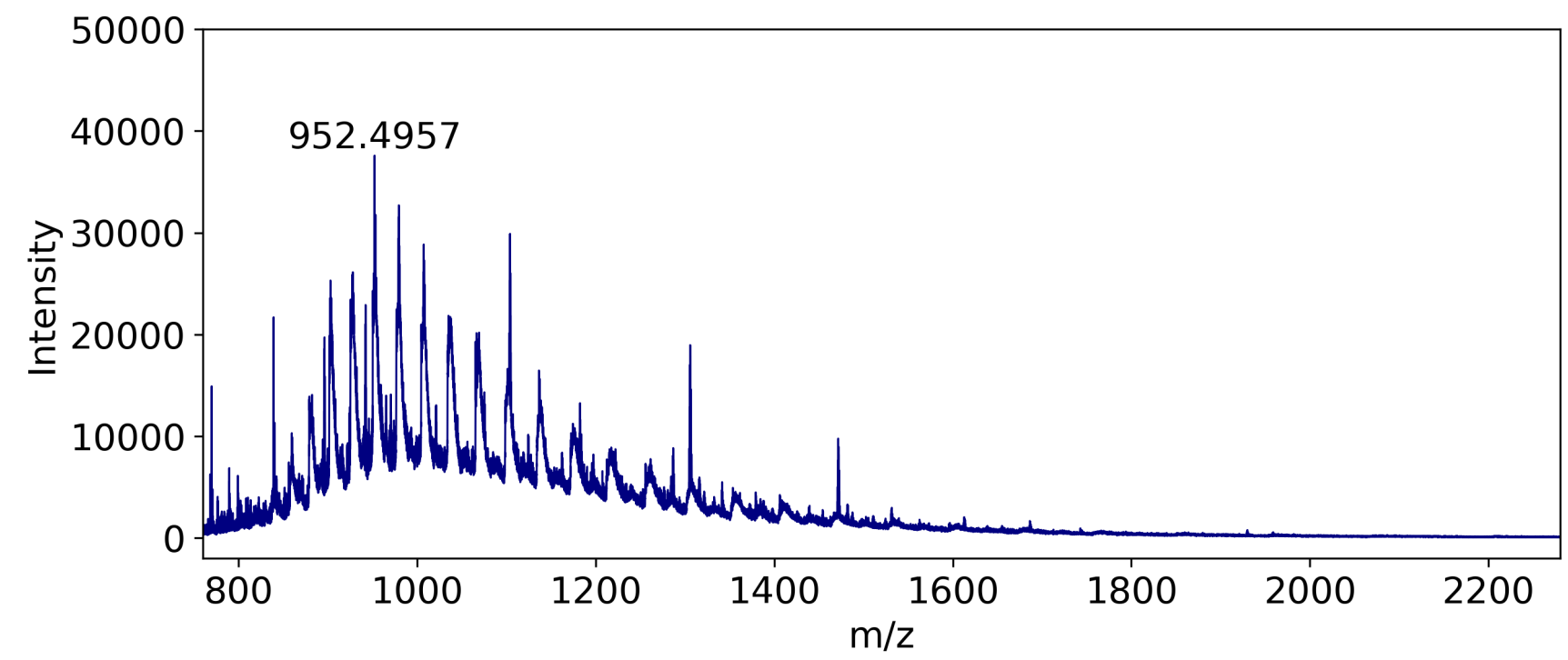

Figure S33. Mass spectrum of thioredoxin reductase at $500 \mu \mathrm{L} / \mathrm{min}$ flow with $300 \mu \mathrm{L} / \mathrm{min} 10 \%$ DMSO sprayed from the second nebulizer. 

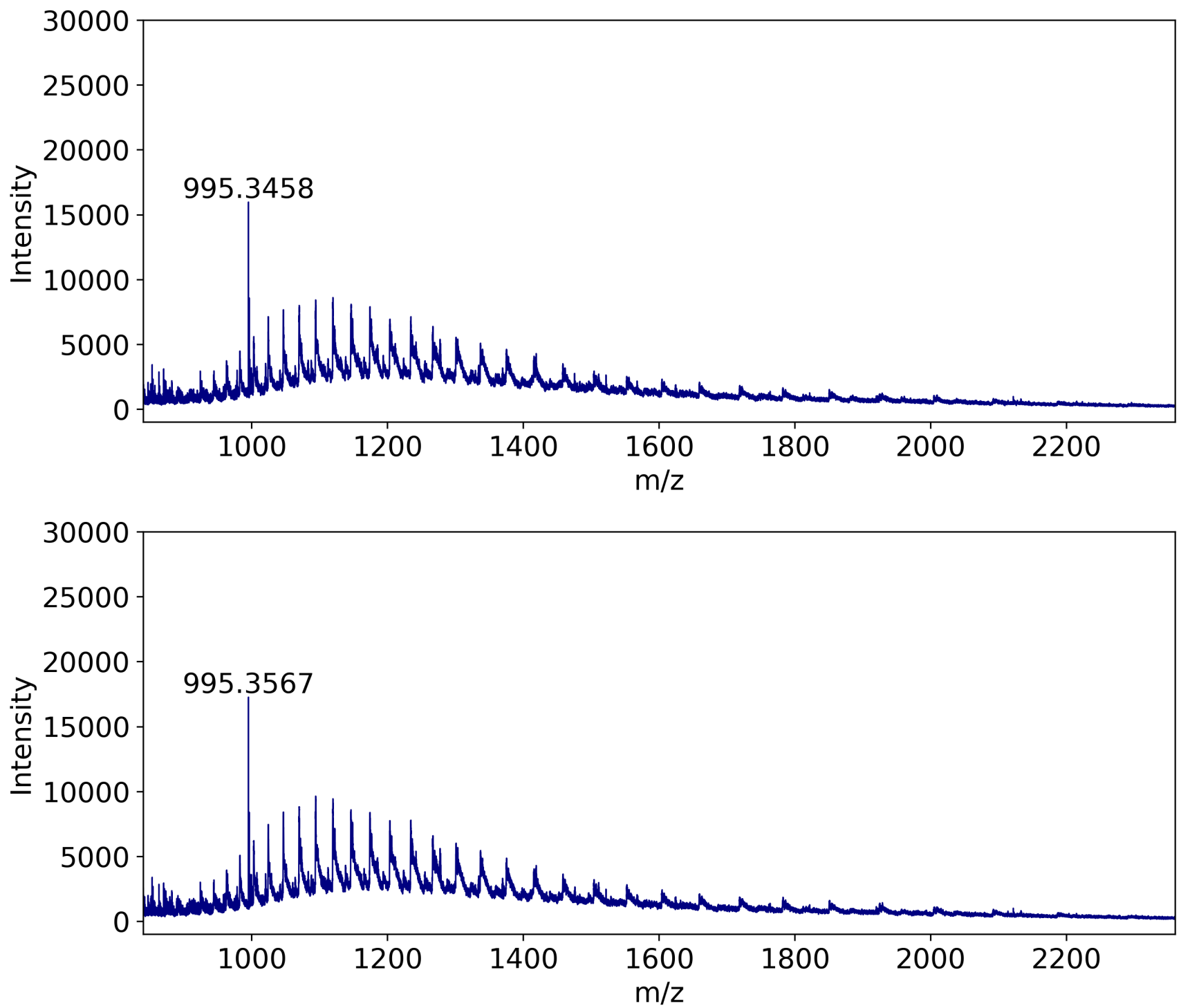

Figure S34. Mass spectrum of $A_{2 A}$ at $500 \mu \mathrm{L} / \mathrm{min}$ flow. 

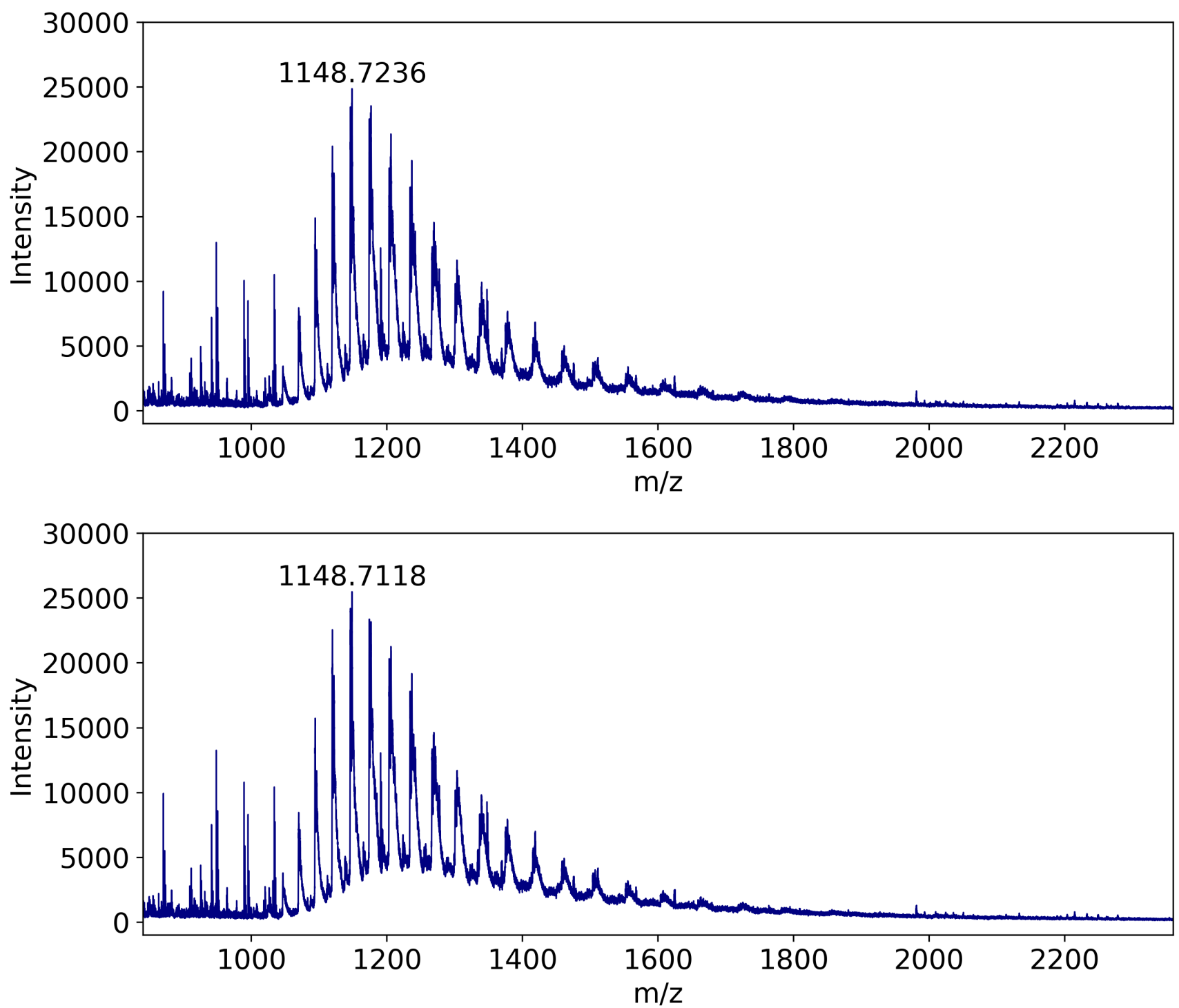

Figure S35. Mass spectrum of $\mathrm{A}_{2 \mathrm{~A}}$ at $500 \mu \mathrm{L} / \mathrm{min}$ flow with $300 \mu \mathrm{L} / \mathrm{min} 10 \%$ DMSO sprayed from the second nebulizer. 

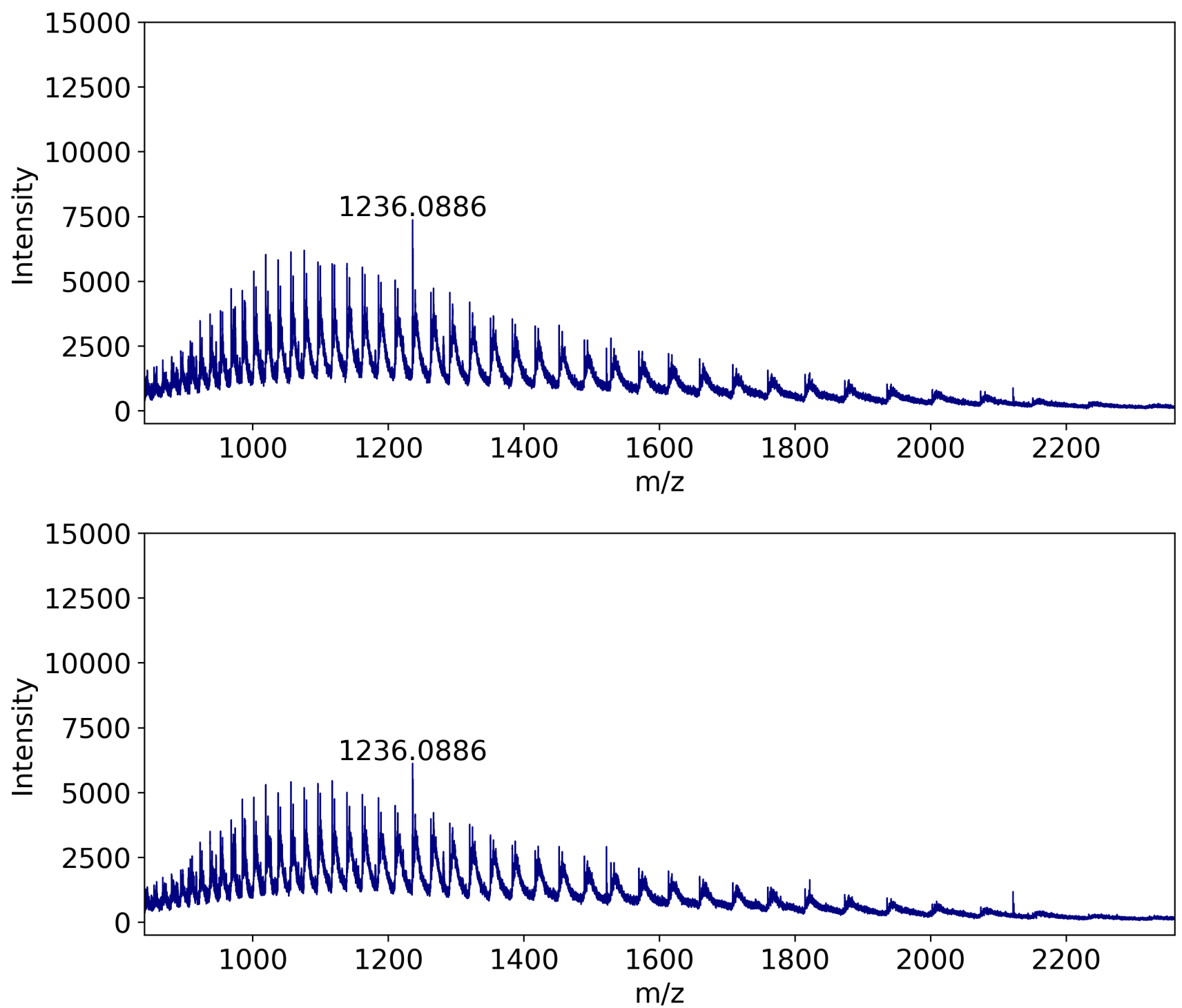

Figure S36. Mass spectrum of KOR at $500 \mu \mathrm{L} / \mathrm{min}$ flow. 

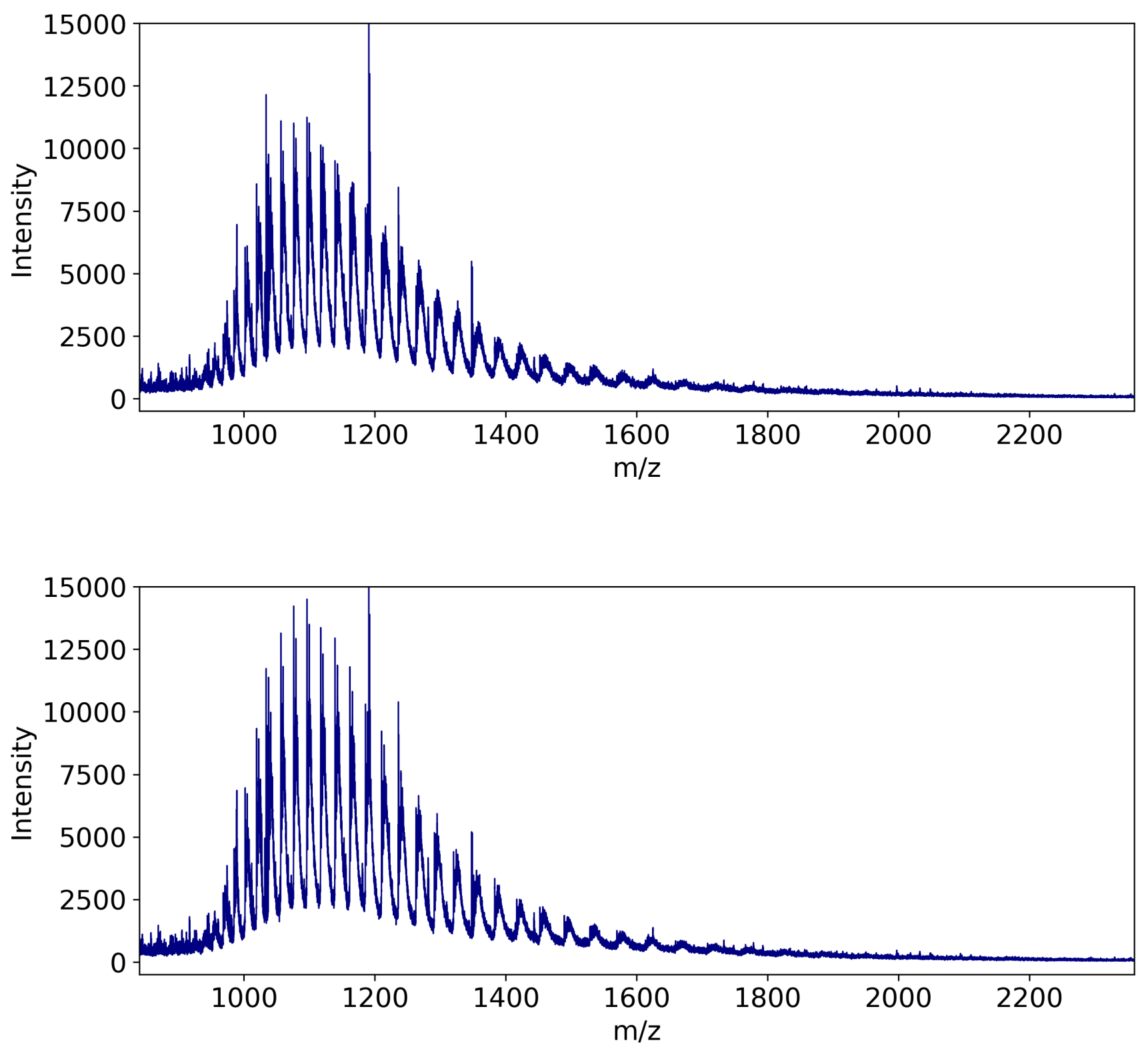

Figure S37. Mass spectrum of KOR at $500 \mu \mathrm{L} / \mathrm{min}$ flow with $300 \mu \mathrm{L} / \mathrm{min} 10 \%$ DMSO sprayed from the second nebulizer. 


\section{Utilization $m-N B A$}
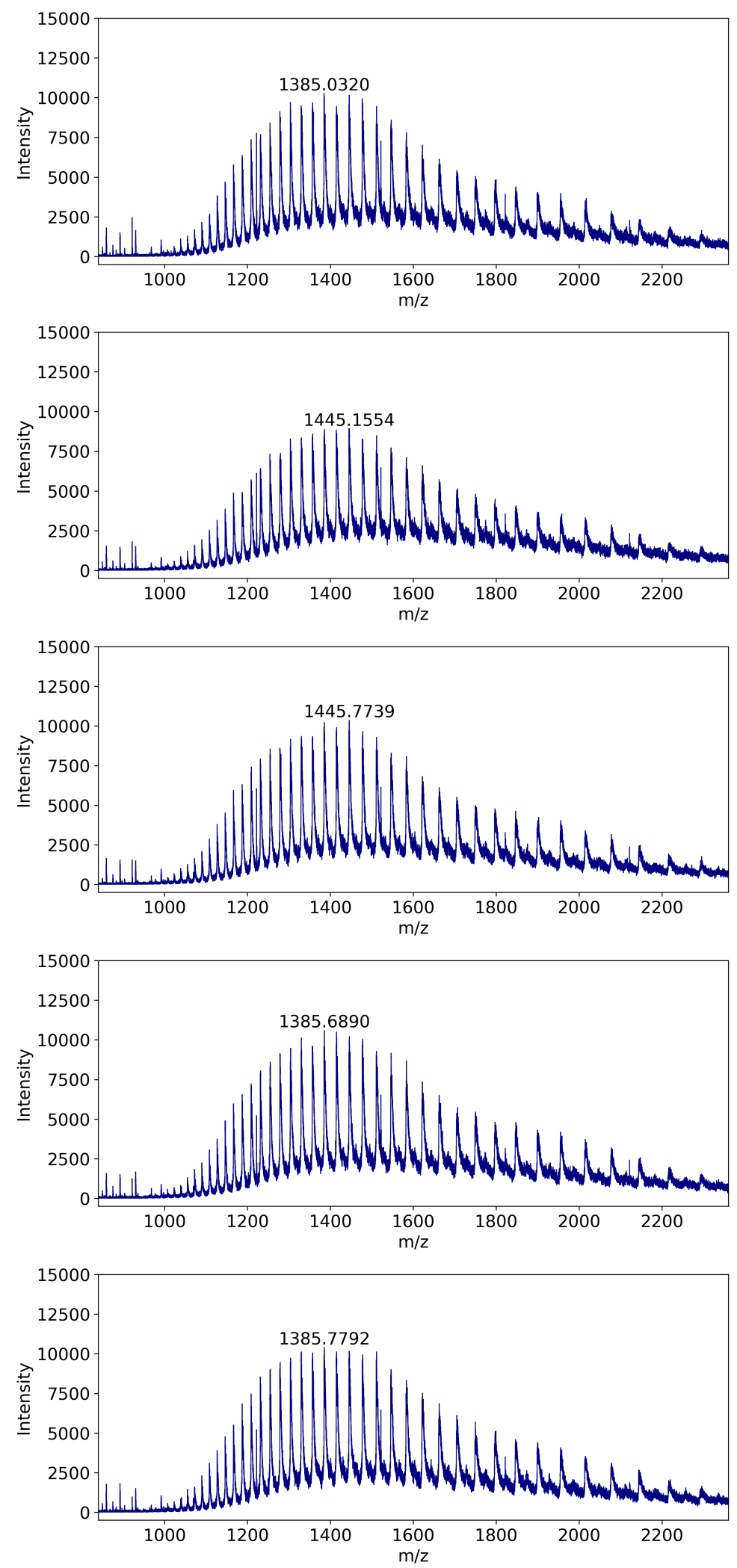

Figure S38. Mass spectrum of BSA at $500 \mu \mathrm{L} / \mathrm{min}$ flow. 

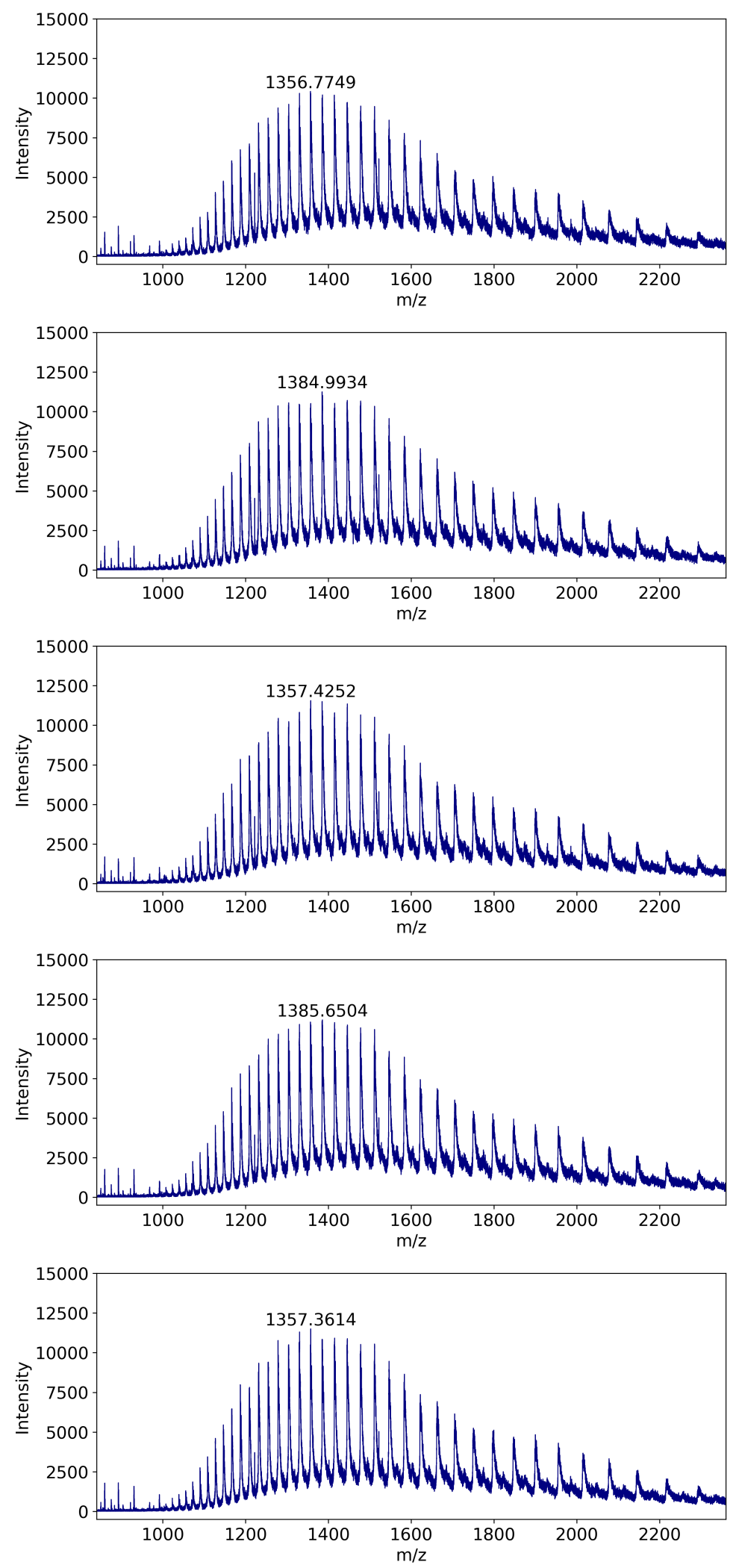

Figure S39. Mass spectrum of BSA at $500 \mu \mathrm{L} / \mathrm{min}$ flow with $300 \mu \mathrm{L} / \mathrm{min}$ water sprayed from the second nebulizer. 

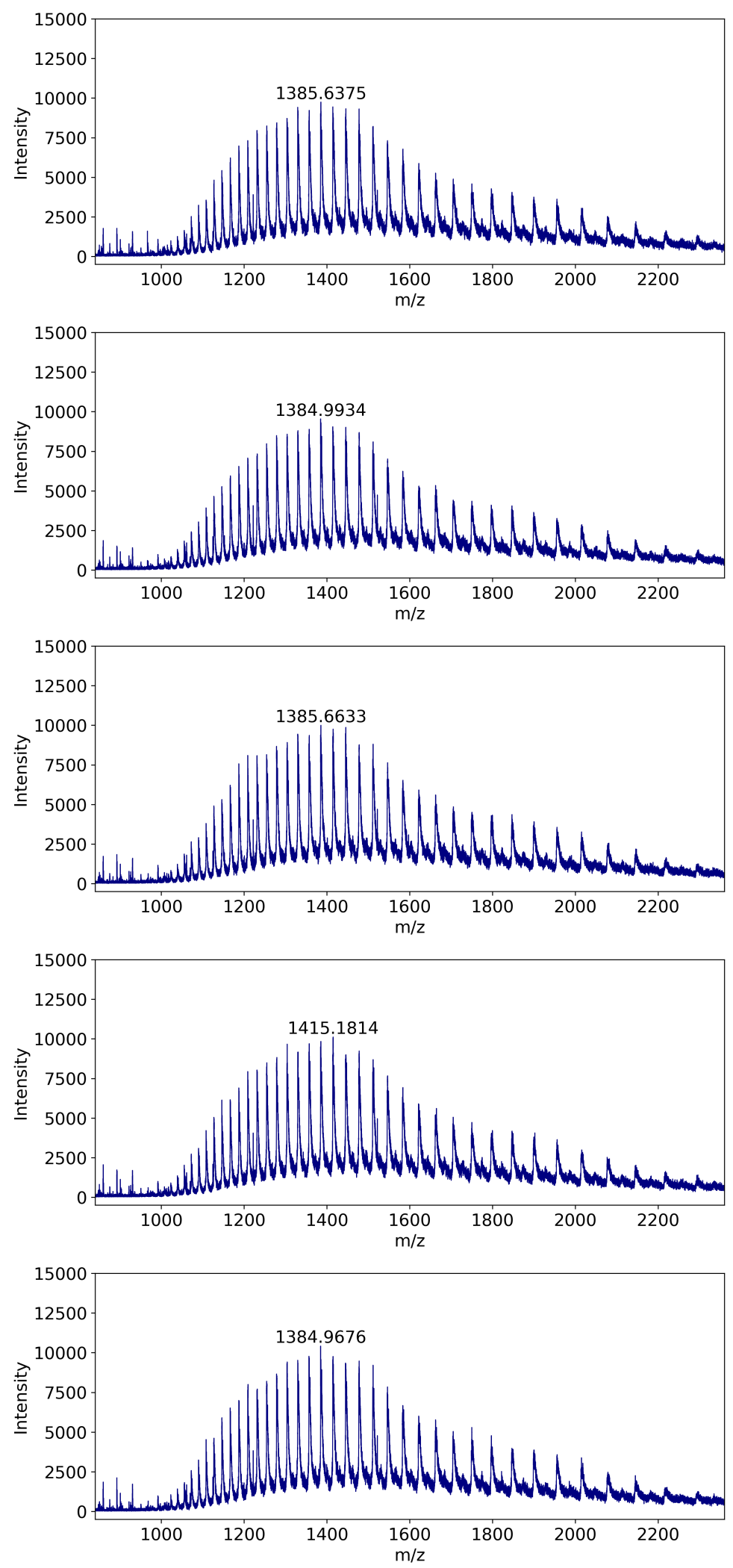

Figure S40. Mass spectrum of BSA at $500 \mu \mathrm{L} / \mathrm{min}$ flow with $300 \mu \mathrm{L} / \mathrm{min} 0.1 \% m$-NBA sprayed from the second nebulizer. 

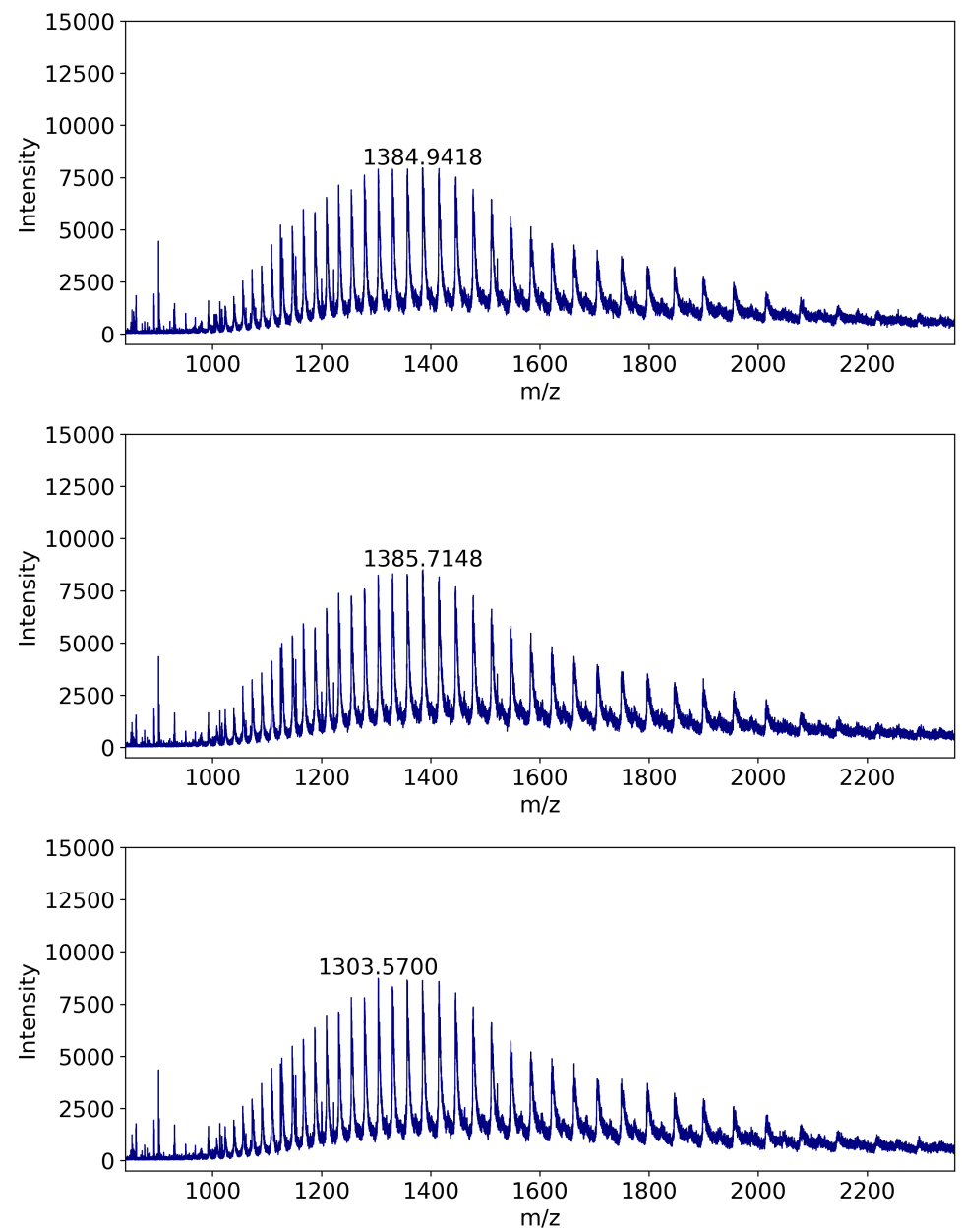

Figure S41. Mass spectrum of BSA at $500 \mu \mathrm{L} / \mathrm{min}$ flow with $300 \mu \mathrm{L} / \mathrm{min} 0.5 \% \mathrm{~m}$-NBA sprayed from the second nebulizer. 

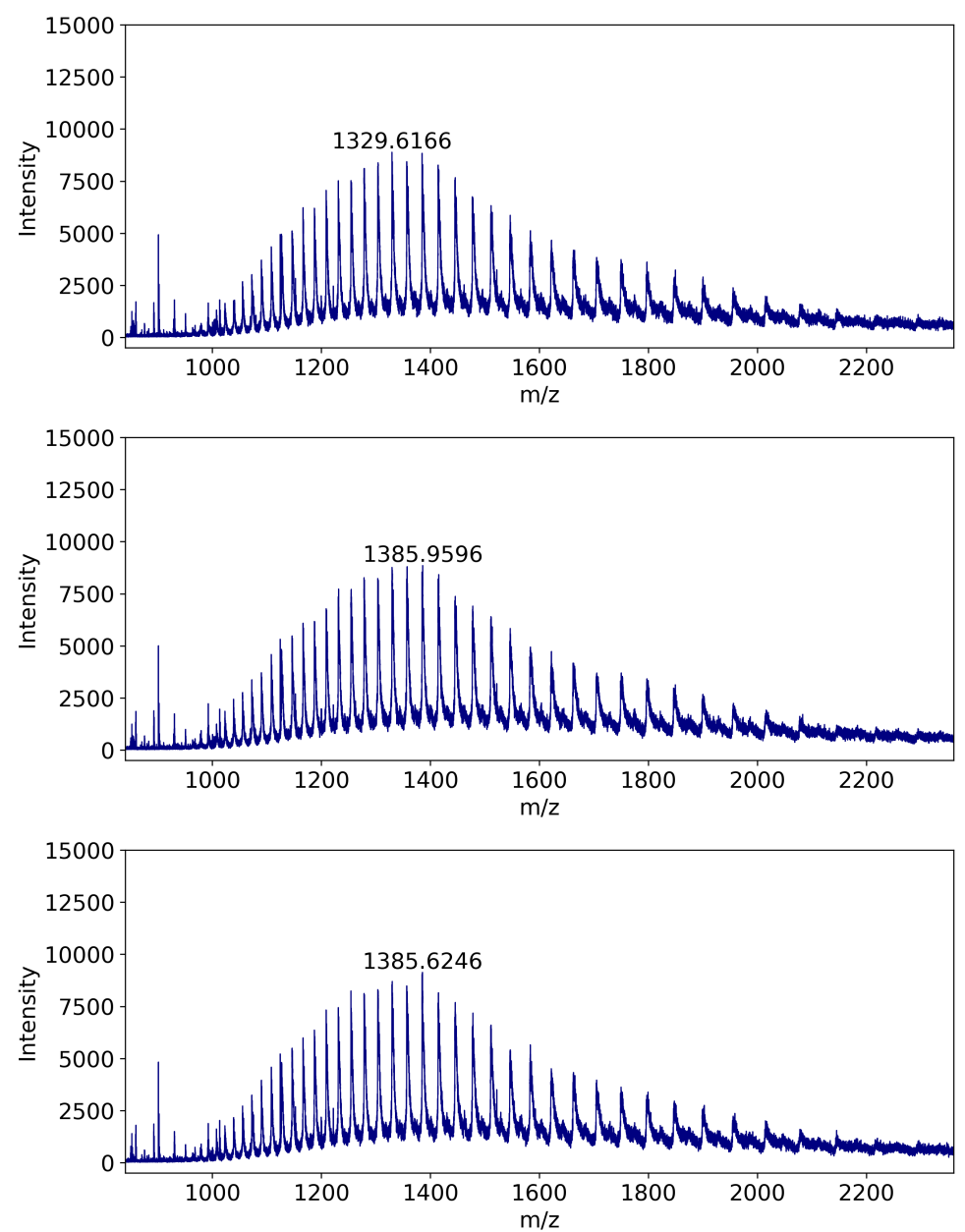

Figure S42. Mass spectrum of BSA at $500 \mu \mathrm{L} / \mathrm{min}$ flow with $300 \mu \mathrm{L} / \mathrm{min} 1 \% m$-NBA sprayed from the second nebulizer. 


\section{References}

1. $\quad$ Lippens, J. L.; Egea, P. F.; Spahr, C.; Vaish, A.; Keener, J. E.; Marty, M. T.; Loo, J. A.; Campuzano, I. D. G., Rapid LC-MS Method for Accurate Molecular Weight Determination of Membrane and Hydrophobic Proteins. Anal. Chem. 2018, 90 (22), 13616-13623.

2. Burykina, J. V.; Boiko, D. A.; Ilyushenkova, V. V.; Eremin, D. B.; Ananikov, V. P., Comprehensive Mass Spectrometric Mapping of Chemical Compounds for the Development of Algorithms for Machine Learning and Artificial Intelligence. Doklady Physical Chemistry 2020, 492 (1), 51-56.

3. Harris, C. R.; Millman, K. J.; van der Walt, S. J.; Gommers, R.; Virtanen, P.; Cournapeau, D.; Wieser, E.; Taylor, J.; Berg, S.; Smith, N. J.; Kern, R.; Picus, M.; Hoyer, S.; van Kerkwijk, M. H.; Brett, M.; Haldane, A.; Del Rio, J. F.; Wiebe, M.; Peterson, P.; Gerard-Marchant, P.; Sheppard, K.; Reddy, T.; Weckesser, W.; Abbasi, H.; Gohlke, C.; Oliphant, T. E., Array programming with NumPy. Nature 2020, 585 (7825), 357-362.

4. $\quad$ NumPy 1.17.2 (https://numpy.org) / accessed February 19, 2021.

5. Pandas 0.25.1 (https://pandas.pydata.org) / accessed February 19, 2021.

6. pyOpenMS 2.6.0 (https://pyopenms.readthedocs.io/en/latest/) / accessed January 25, 2021.

7. Rost, H. L.; Schmitt, U.; Aebersold, R.; Malmstrom, L., pyOpenMS: a Python-based interface to the OpenMS mass-spectrometry algorithm library. Proteomics 2014, 14 (1), 74-77.

8. Hunter, J. D., Matplotlib: A 2D Graphics Environment. Computing in Science \& Engineering 2007, 9 (3), 90-95.

9. Matplotlib 3.3.4 (https://matplotlib.org/) / accessed March 26, 2021. 